\title{
LA ESTRATIGRAFÍA, LOS PROCESOS DEPOSICIONALES Y LA SECUENCIA OCUPACIONAL DE PACHACAMAC
}

\author{
Krzysztof Makowski, Cynthia Vargas $^{b}$ y Domenico Villavicencio ${ }^{c}$
}

\begin{abstract}
Resumen
Los resultados de las investigaciones realizadas desde 2005 por los integrantes del Programa Arqueológico-Escuela de Campo-«Valle de Pachacamac», convenio PUCP-UNACEM, pusieron en evidencia que la apariencia actual de Pachacamac monumental, con una traza planificada que cuenta con tres murallas, asi como con dos largas calles rectas que recorren la parte central del Santuario, de Sur a Norte y de Este a Oeste, se debe, en exclusividad, a la febril actividad de la administración inca. Al parecer, Pachacamac inca carecía de las características de una ciudad con densa y extensa ocupación residencial permanente y su traza estuvo determinada por la función ceremonial de la arquitectura del sitio. Los resultados de nuestras últimas once campañas de excavación realizadas en Pachacamac indican que no han existido continuidades, ni en el diseño arquitectónico ni en la traza, a lo largo de los cinco periodos de ocupación humana sucesivos en el sitio. Es más, cada uno de los periodos se caracteriza por contar con tipos diferentes de arquitectura y distinta distribución espacial, en comparación con los demás, siendo la administración Inca la que habría emprendido la tarea de construir un gran centro ceremonial con espacios destinados para albergar temporalmente a los peregrinos (campamentos y pirámides con rampa, esta últimas incluian quizás templetes de dioses locales), ejes de comunicación (calles y plazas) y templos de culto imperial (del Sol y de Pachacamac). Los objetivos de este artículo son presentar y discutir la compleja estratigrafía que cubre toda la historia de Pachacamac, desde la construcción del Templo Viejo hasta su abandono definitivo en la segunda mitad del siglo XVI, y demostrar que el factor predominante en su formación es antrópico; por lo que, la complejidad y espesor de cada capa no guarda relación directa con la duración del periodo al que corresponde, sino con la intensidad de las actividades constructivas y en el número de personas involucradas. De esta manera, los estratos correspondientes cronológicamente al periodo más corto, el Horizonte Tardío, superan en espesor y complejidad a los demás.
\end{abstract}

Palabras clave: Pachacamac, El Cuadrángulo, Periodo Colonial Temprano, Horizonte Tardio, Inca, Ychsma, Horizonte Medio, Cultura Lima, estratigrafia.

\section{Abstract \\ STRATIGRAPHY, DEPOSITIONAL PROCESSES AND THE OCCUPATIONAL SEQUENCE OF PACHACAMAC}

The results of the investigations carried out since 2005 by the members of the Archaeological Program-Field School"Pachacamac Valley", PUCP-UNACEM agreement, made it clear that the current appearance of monumental Pachacamac, with a planned layout that has three walls, as well as two long straight streets that run through the central part of the Sanctuary, from South to North and from East to West, is due, exclusively, to the feverish activity of the Inca administration. Apparently, Inca Pachacamac lacked the characteristics of a city with dense and extensive permanent residential occupation and its layout was determined by the ceremonial function of the site's architecture. The results of our last 11 excavation campaigns conducted at Pachacamac indicate that there have been no continuities, either in the architectural design or in the layout, throughout the five successive periods of human occupation that occurred at the

a https://orcid.org/0000-0002-1523-1624 Pontificia Universidad Católica del Perú, Programa ArqueológicoEscuela de Campo-«Valle de Pachacamac», kmakows@pucp.edu.pe

b https://orcid.org/0000-0002-7687-4885 Pontificia Universidad Católica del Perú, Programa ArqueológicoEscuela de Campo-«Valle de Pachacamac», cvargasc@pucp.edu.pe

c https://orcid.org/0000-0002-4865-6055 Pontificia Universidad Católica del Perú, Programa ArqueológicoEscuela de Campo-«Valle de Pachacamac», dvillavicencio@pucp.pe 
site. Furthermore, each of the periods is characterized by different types of architecture and different spatial distribution, compared to the others. From this, it can be inferred that it is the Inca administration that undertook the task of building a great ceremonial center with spaces destined to temporarily house the pilgrims (camps and pyramids with a ramp, the latter perhaps including temples of local gods), communication axes (streets and plazas) and temples of imperial worship (of the Sun and Pachacamac). The objectives of this article are to present and discuss the complex stratigraphy that covers the entire history of Pachacamac, from the construction of the Old Temple to its definitive abandonment in the second half of the 16th century. As well as, to demonstrate that the predominant factor in its formation is anthropic, so the complexity and thickness of each layer is not directly related to the length of the period to which it corresponds, but to the intensity of the constructive activities and the number of people involved. In this way, the layers corresponding chronologically to the shortest period, the Late Horizon, exceed the others in thickness and complexity.

Keywords: Pachacamac, El Cuadrángulo, Early Colonial Period, Late Horizon, Inca, Ychsma, Middle Horizon, Lima Culture, stratigraphy.

\section{Introducción}

Las investigaciones del Programa Arqueológico-Escuela de Campo-«Valle de Pachacamac», convenio PUCP-UNACEM, se realizan de manera ininterrumpida en el valle bajo de Lurín, llamado Ychsma antes de la conquista por el Tahuantinsuyu, desde hace treinta años.

A partir del año 2005 se iniciaron los trabajos de campo en el Santuario de Pachacamac (Fig. 1). Los resultados de excavaciones, revisiones bibliográficas y estudios de laboratorio sugirieron que el imperio inca modificó sustancialmente el paisaje del valle de Ychsma e impuso a este río y, asimismo al oráculo, un nuevo nombre, Pachacamac (hoy Lurín) (Curatola 2016).

Desde hace 16 años, el Programa Arqueológico-Escuela de Campo-«Valle de Pachacamac», ha concentrado sus esfuerzos en revisar las hipótesis acerca de la secuencia arquitectónica y ocupacional de Pachacamac, a partir de los resultados de las excavaciones estratigráficas en área llevadas a cabo en temporadas anuales que abarcan de tres a cinco meses de campo cada una (Tabla 1).

A partir del año 2013, después de haber definido la cronología de las tres murallas y de la calle Norte-Sur, nos hemos dedicado a la excavación, a gran escala, de un edificio sin paralelo en Pachacamac, ubicado al pie del Templo Viejo y al final de la calle Norte-Sur, denominado El Cuadrángulo.

Conforme con la percepción comúnmente aceptada (Ángeles y Pozzi-Escot 2010; Lumbreras 2017) de que las actividades ceremoniales y administrativas de los periodos Lima, Wari e Ychsma aportaron por igual a la formación de la traza arquitectónica visible en la superficie en Pachacamac, así como a la superposición de niveles de uso, estructuras, rellenos constructivos, capas de destrucción y descarte; el periodo inca solo habría dejado vestigios monumentales en las periferias del núcleo urbano preexistente, además de dispersos casos de reocupación de edificios construidos en las épocas anteriores. De acuerdo con esta hipótesis, solo un nivel estratigráfico, debajo de la capa superficial, correspondería a eventos del Periodo Horizonte Tardío. Los estratos subyacentes son automáticamente asignados a actividades del Periodo Intermedio Tardío (Eeckhout 1999b; Franco y Paredes 2016). Régulo Franco y Ponciano Paredes (2016), siguiendo estos supuestos, fechan la construcción de El Cuadrángulo dentro del Periodo Intermedio Tardío, con eventuales antecedentes en el Horizonte Medio; al igual que el Templo Pintado, vecino al Oeste.

Los resultados de nuestras campañas de excavación, realizadas tanto dentro de El Cuadrángulo como fuera de él, nos llevaron a una conclusión que discrepa de las arriba expuestas. Los periodos que se caracterizan por una mayor complejidad estratigráfica, debido a la gran intensidad de eventos de construcción, reconstrucción y también de actividades ceremoniales, son aquellos que se definen por la presencia de material diagnóstico Lima Medio, por un lado; e Inca e Ychsma Tardío asociados, por el otro. En este último caso, se logran definir varios episodios constructivos 


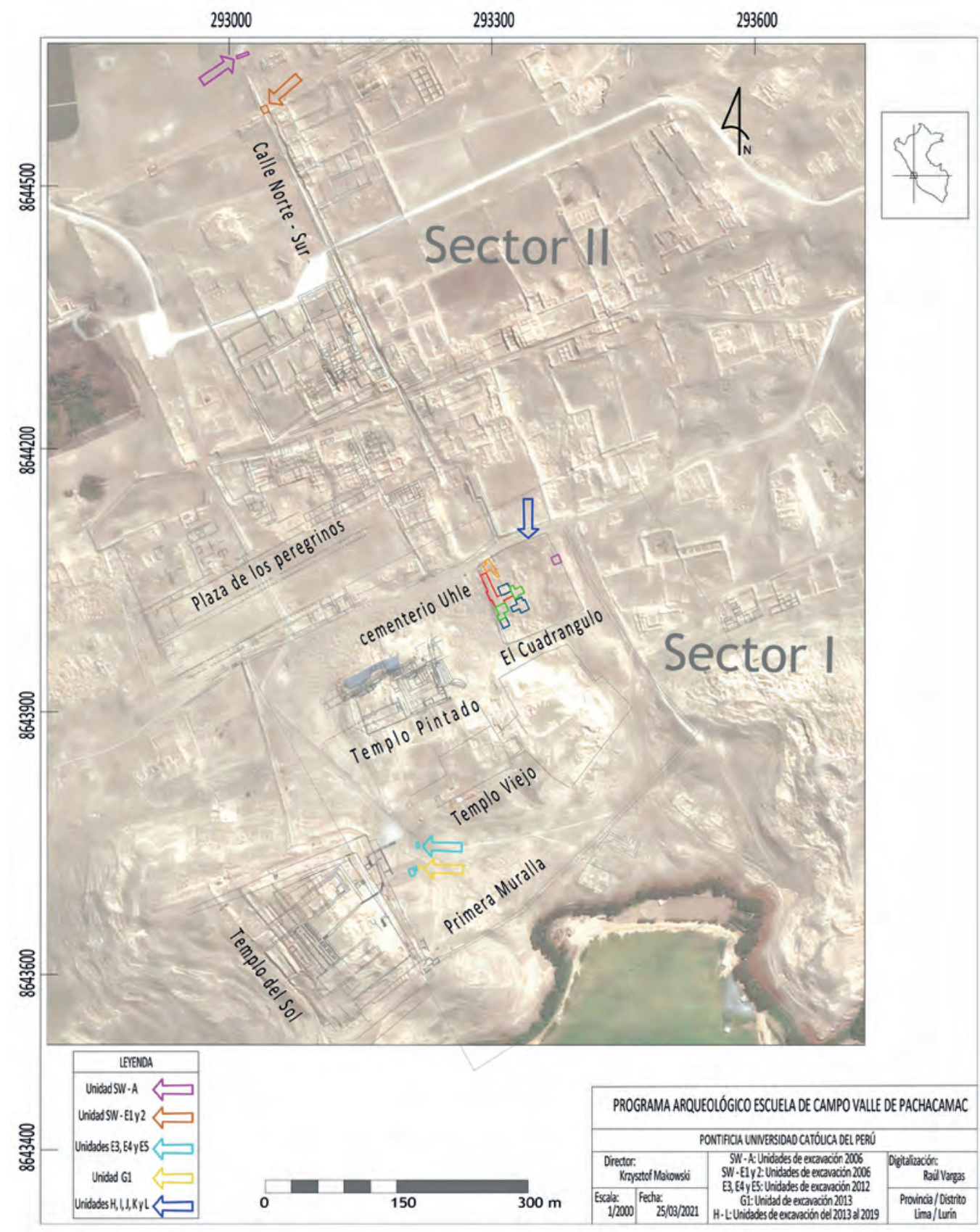

Figura 1. Plano de Pachacamac con la ubicación de los sectores excavados y discutidos en el texto (dibujo: Raúl Vargas, PATL). 


\begin{tabular}{|c|c|c|c|c|c|c|}
\hline Años d.C. & Periodos & Estilos locales & \multicolumn{2}{|c|}{$\begin{array}{l}\text { Imitaciones de estilo } \\
\text { foráneos }\end{array}$} & $\begin{array}{l}\text { Edificios prin- } \\
\text { cipales }\end{array}$ & $\begin{array}{l}\text { Fechas C14 (cal. } \\
\text { Oxcal: Eeckhout, } \\
\text { 2018) }\end{array}$ \\
\hline $1532-1572$ & $\begin{array}{l}\text { Colonial } \\
\text { Temprano } \\
\text { (Transicional) }\end{array}$ & Ychsma Tardío B & \multicolumn{2}{|l|}{$\begin{array}{l}\text { Inca, } \\
\text { Chimú-Inca }\end{array}$} & $\begin{array}{l}\text { El Cuadrángulo } \\
\text { (Tambo) }\end{array}$ & \\
\hline $1450-1532$ & $\begin{array}{l}\text { Horizonte } \\
\text { Tardío }\end{array}$ & $\begin{array}{l}\text { Ychsma Tardío } \\
\text { A/B }\end{array}$ & \multicolumn{2}{|l|}{$\begin{array}{l}\text { Inca, } \\
\text { Chimú-Inca }\end{array}$} & $\begin{array}{l}\text { Calles amura- } \\
\text { lladas, Templo } \\
\text { del Sol, Templo } \\
\text { de Pachacamac, } \\
\text { Acllawasi, PCR } \\
\mathrm{N}^{\circ} 1,2,4,8\end{array}$ & \\
\hline $1370-1450$ & \multirow{3}{*}{$\begin{array}{l}\text { Intermedio } \\
\text { Tardío }\end{array}$} & Ychsma Tardío A & & & PCR No3 & \\
\hline $1200-1370$ & & $\begin{array}{l}\text { Ychsma } \\
\text { Temprano y } \\
\text { Medio } \\
\end{array}$ & & & $\begin{array}{l}\text { Templo del } \\
\text { Mono }\end{array}$ & \\
\hline $1000-1200$ & & $\begin{array}{l}\text { Ychsma } \\
\text { Temprano }\end{array}$ & \multicolumn{2}{|l|}{ Tricolor } & & $\begin{array}{l}\text { Tricolor: } 1040 \text { - ? } \\
\text { d.C. (estimación) }\end{array}$ \\
\hline $800-1000$ & \multirow{2}{*}{$\begin{array}{l}\text { Horizonte } \\
\text { Medio }\end{array}$} & Ychsma Inicial & \multicolumn{2}{|l|}{$\begin{array}{l}\text { Pachacamac, } \\
\text { Huamanga- } \\
\text { Viñaque, } \\
\text { Teatino, } \\
\text { Epigonal }\end{array}$} & & $\begin{array}{l}\text { Ychsma Inicial: } \\
\text { 890-1220 d.C. } \\
\text { Epigonal } \\
\text { (Huamanga): } \\
\text { 990-1160 d.C. } \\
\text { Pachacamac B: } \\
980 \text { - } 1050 \text { d.C. }\end{array}$ \\
\hline $600-800$ & & $\begin{array}{l}\text { Lima Tardío: } \\
\text { Maranga/ } \\
\text { Nievería }\end{array}$ & & $\begin{array}{l}\text { Imitaciones } \\
\text { Wari }\end{array}$ & Adobitos & $\begin{array}{l}\text { Nievería y } \\
\text { Maranga: } 670- \\
780 \text { d.C. } \\
\text { Lima Tardío } \\
\text { - Maranga: } 650- \\
780 \text { d.C. }\end{array}$ \\
\hline $300-600$ & \multirow{2}{*}{$\begin{array}{l}\text { Intermedio } \\
\text { Temprano }\end{array}$} & $\begin{array}{l}\text { Lima Temprano- } \\
\text { Medio: Playa } \\
\text { Grande }\end{array}$ & & & Templo Viejo & \\
\hline $100-300$ & & Villa El Salvador & $\begin{array}{l}\text { Imitaciones } \\
\text { Topará y } \\
\text { Nasca }\end{array}$ & & & \\
\hline
\end{tabular}

Tabla 1. Cuadro cronológico de Pachacamac. 
y de uso inca, anteriores a la presencia española, y también ocupaciones relacionadas con la transformación de El Cuadrángulo en un tambo colonial durante el siglo XVI, antes de la fundación de la reducción de San Salvador de Pachacamac.

En los siguientes párrafos analizaremos los cambios de uso del espacio al interior de la Primera Muralla, a partir de la secuencia estratigráfica que cubre toda la historia de Pachacamac, desde la construcción del Templo Viejo hasta su abandono definitivo en el siglo XVI.

\section{Secuencia ocupacional en Pachacamac}

A juzgar por las publicaciones y diarios de campo de arqueólogos que han trabajado en Pachacamac, el famoso santuario y oráculo inca en el valle de Lurín (Ychsma), desde Uhle (2003 [1903]) hasta nuestros días, parecen haber compartido una serie de prejuicios y, relacionadas con ellos, expectativas acerca de las características de la estratigrafía. Entre estas suposiciones es menester mencionar, en primera instancia, dos de ellas:

1. La idea de que la organización espacial de Pachacamac, con tres áreas circundadas parcial o totalmente por igual número de murallas y con las calles amuralladas Norte-Sur y Este-Oeste, antecede por varios siglos la época inca, siendo establecida, probablemente, en el Horizonte Medio (Patterson 1966; Eeckhout 1999a,b; Shimada et al. 2010; Makowski 2016b).

2. La expectativa de encontrar una superposición simple de estratos, similar en todo el asentamiento, con el grosor de cada capa directamente proporcional a la duración de los periodos subsiguientes. Por consiguiente, se podía esperar que la estratigrafía definida en un sector podía proporcionar una secuencia maestra para todo el sitio (Shimada 1991; Eeckhout 2010a; Ramos y Paredes 2010; Makowski 2016a).

Estos prejuicios, a su vez, han condicionado la interpretación de la secuencia cronológica y de la organización espacial del sitio. Contrariamente a la hipótesis inicial de Uhle (2003 [1903]), quien atribuía, de manera acertada, la traza planificada a los incas, se consideraba, a partir de las excavaciones de Strong y Corbett (1943), Tello (1940, 1960, 2007), Giesecke (1938), Franco y Paredes (2016), Ramos (2011), y recientemente Eeckhout (2010a,b) y Shimada (2007), que la ocupación definida por la presencia de las imitaciones de cerámica cuzqueña se reduce a un solo nivel cercano a la superficie que corresponde a los ańos 1470-1531/2.

Asimismo, las construcciones emprendidas por encargo de la administración del Tahuantinsuyo se habrían distribuido de manera preferente en la periferia del núcleo constituido por las pirámides con rampa, el Templo Viejo y el Templo Pintado, siendo edificaciones enumeradas atribuidas a la segunda mitad del Periodo Intermedio Temprano, el Periodo Horizonte Medio y el Periodo Intermedio Tardío (Jiménez Borja 1985; Eeckhout 1999a,b, 1999-2000, 2004a,b,c; Ángeles y Pozzi-Escot 2010; Bernuy y Pozzi-Escot 2018).

La manera de concebir a priori las características de la estratigrafía horizontal y vertical en Pachacamac ha condicionado interpretaciones variadas acerca de la cronología ocupacional del sitio, como las de Jiménez Borja (1985) o Eeckhout (1999a,b, 1999-2000, 2004b). El primero de los investigadores citados interpreta las plataformas cercadas con rampa (PCR), distribuidas entre la segunda y la tercera muralla, como templos de culto de deidades ancestrales de la familia del dios Pachacamac, en uso hasta la extirpación de idolatrías en el siglo XVI. En cambio, Eeckhout (1999a,b, 1999-2000, 2004b) los considera palacios de señores que gobernaban al curacazgo Ychsma en el Periodo Intermedio Tardío, y, por lo tanto, se trataría de construcciones previas a la conquista incaica del valle. La reocupación inca de las PCR habría tenido carácter esencialmente doméstico. Recientemente, Eeckhout (2010a) ha matizado su propuesta admitiendo que ciertas PCR fueron construidas durante el Periodo Horizonte Tardío.

Las conclusiones a las que hemos podido llegar, a partir de los resultados de nuestras excavaciones en Pachacamac, llevadas a cabo anualmente desde el ańo 2005, difieren en varios aspectos 
de las ideas imperantes en la literatura con respecto al tema de la estratigrafía y de la cronología arquitectónica de Pachacamac (Shimada 1991; Ravines 1996; Eeckhout 2010a,b; Ramos 2011). En las temporadas mencionadas hemos excavado, aproximadamente, 3000 metros cuadrados en 66 unidades. Estas fueron distribuidas de manera estratégica con el fin de poder fechar —a partir de la estratigrafía y de las asociaciones con cerámica diagnóstica, en particular, las imitaciones de la cerámica cuzqueña y estilos asociados como el chimú-inca - la construcción de las entradas a través de las tres murallas, de las calzadas y de los muros laterales de las calles, así como de las portadas y vestíbulos. Las excavaciones fueron complementadas con una prospección con radar de penetración de suelos y con magnetometría.

Entre las principales conclusiones a las que nos hemos referido anteriormente, se puede mencionar que la estratigrafía de Pachacamac revela notables diferencias en la intensidad de las actividades humanas que se llevaron a cabo en diferentes periodos y fases sucesivas registradas en el santuario-oráculo. Estas diferencias se expresan materialmente en el carácter y el grosor de las deposiciones de suelos y de rellenos constructivos que se han acumulado en tiempos relativamente cortos.

Comparativamente, en la mayoría de los lugares excavados por nosotros, las actividades del corto periodo inca y de las décadas de la presencia española, previa a la reducción de San Salvador de Pachacamac de 1572, dejaron, paradójicamente, la huella de mayor contundencia en cuanto al grosor y la complejidad de estratigrafías, y de estructuras arquitectónicas asociadas.

Ambos periodos arriba mencionados, incluyendo el Periodo Colonial Temprano, se caracterizan por la presencia de los estilos de cerámica Ychsma Tardío e Inca Provincial, y la ausencia de fragmentos de vasijas coloniales, hechas con el uso de tecnología europea, en torno y/o recubiertas de esmalte vidriado. El único periodo comparable con el Horizonte Tardío, desde el punto de vista de la intensidad de actividades, es la segunda mitad del Periodo Intermedio Temprano (Lima Medio). En cambio, las evidencias relacionadas con la presencia de estilos cerámicos del Horizonte Medio, como Lima Tardío, Huamanga (Cabrera y Ochatoma 2016), Viñaque (Epigonal de Uhle 2003 [1903]) e Ychsma Inicial (Bazán 1990) son limitadas, salvo en áreas funerarias. Lo mismo concierne a las fases Ychsma Temprano y Medio preincas del Periodo Intermedio Tardío.

El vestíbulo de la entrada principal al Templo del Sol y la contigua trinchera de Strong y Corbett (1943) ofrecen un buen punto de partida para ilustrar y sustentar las conclusiones que acabamos de exponer (Fig. 2).

En la entrada al Templo del Sol hemos definido dos periodos de actividades constructivas, separados por un amplio hiatus. Uno de ellos está relacionado con la cerámica Lima Medio (4, 5 de Patterson 1966) y el otro, con tres fases subsiguientes, se caracteriza por la recurrencia de la cerámica Cuzco Polícromo, Provincial.

La primera fase en la secuencia del Horizonte Tardío se relaciona con la construcción del muro de adobe, revestido de piedra, correspondiente a la primera terraza y al vestíbulo del ingreso al Templo del Sol. Este muro fue seriamente dañado a raíz de un fuerte movimiento sísmico y luego, reconstruido durante la segunda fase. Llama la atención que la calidad de este segundo muro sea menor que la del primero y que este, a diferencia del primero, no esté revestido de rocas canteadas. Ambas fases se relacionan, evidentemente, con la presencia de la cerámica Cuzco Polícromo.

La tercera fase corresponde a la destrucción parcial del vestíbulo a causa de las fuertes precipitaciones pluviales, seguida por el crecimiento de los montículos estratificados de desechos orgánicos, localizados al pie de la primera terraza del templo y a ambos lados de la entrada. Se encontraron hasta tres episodios sucesivos del masivo descarte de esteras y elementos estructurales de materiales perecibles, ocasionalmente quemados, así como fragmentos de cerámica ceremonial inca de gran calidad.

Una secuencia similar hemos registrado al excavar parte del perfil de la famosa trinchera de Strong y Corbett (1943), la que corta la fachada oriental del Templo del Sol, bajando por la 

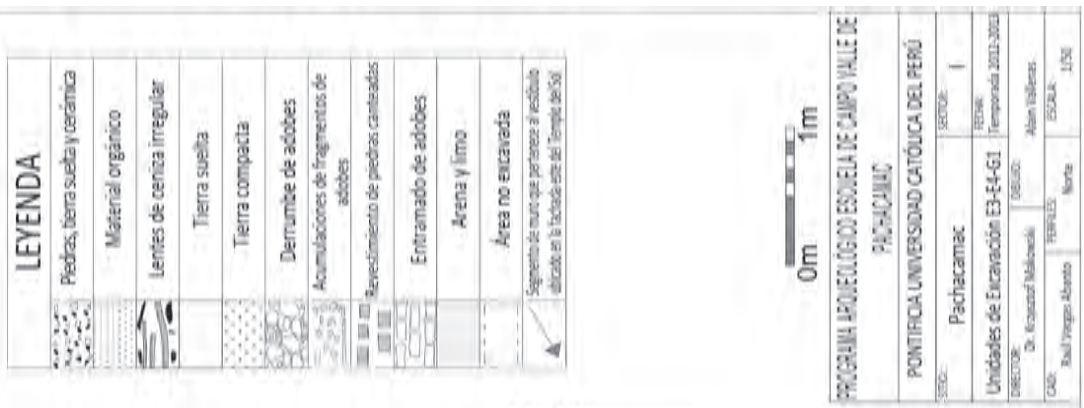

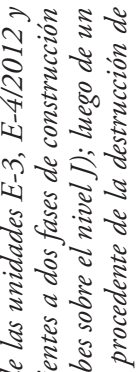

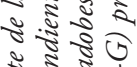

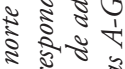

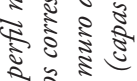

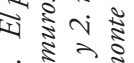

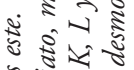

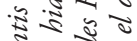

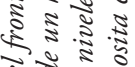

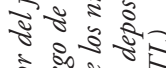

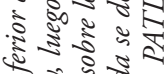

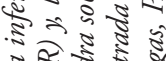

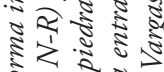

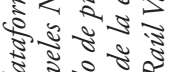

5. 3.8 . 3

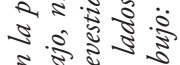

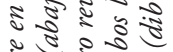

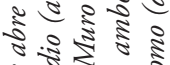

\&

a)

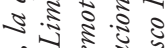

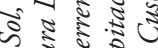

ปั

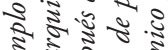

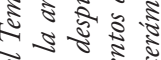

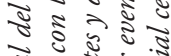

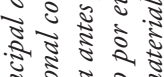

․ำ 8 .

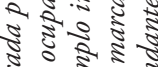

吾. 8 .

2 3 ะ 8

ช

2. 농ำ

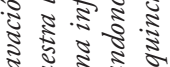

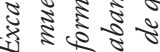

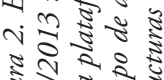

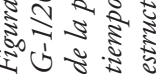



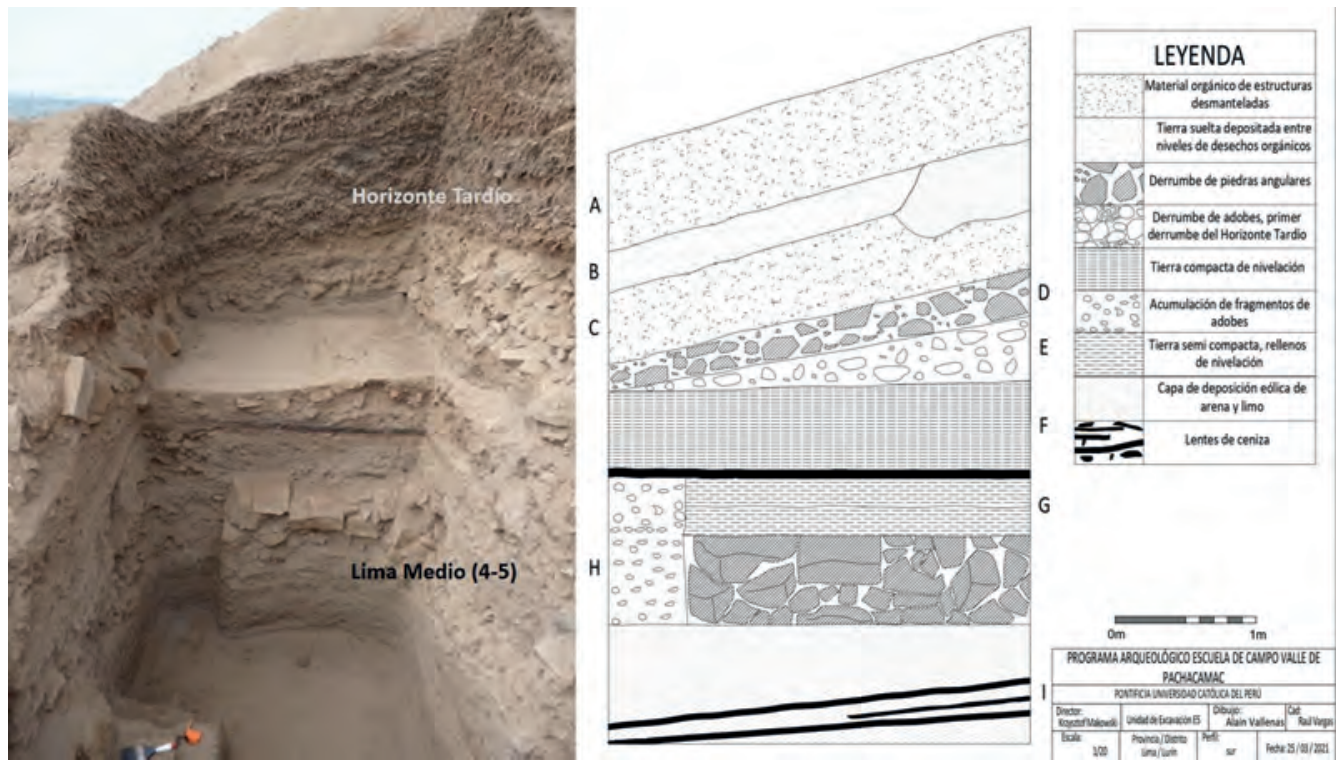

Figura 3. Excavación (unidad E-5/2012) de un segmento del perfil sur de la trinchera de Strong y Corbett (1943). Dibujo de perfil sur con la secuencia estratigráfica comparable con la de la entrada del Templo del Sol: niveles del Horizonte Tardio (A-D) sobrepuestos a las de Lima Medio (E-H), siendo separadas por un delgado estrato coluvial (fotografia y dibujo: Raúl Vargas, PATL).

pendiente al norte del acceso principal (Fig. 3). En este caso, se logró llegar a nivel estéril y la secuencia de eventos ocupacionales sobrepuestos, con material Lima, resaltó al ser más compleja que en el caso precedente. Adicionalmente, debajo de niveles Lima, se encontraron superficies de uso con cerámica tipo Villa El Salvador. A diferencia de lo afirmado por Patterson (1966) en su estudio del material de Strong y Corbett, no hemos encontrado materiales Lima Tardío - Maranga, sino, exclusivamente, fragmentos de cerámica Lima Medio. Encima de la relativamente delgada capa correspondiente al nivel de la construcción del Templo del Sol, también se encontraron montículos de basura acumulados en el Periodo Colonial Temprano y, posiblemente, relacionados con los episodios de la destrucción del santuario, así como de la expulsión del personal del templo que vivía o trabajaba en las estructuras de material perecible, construidas sobre las terrazas.

Otros casos de secuencias estratigráficas, mucho más complejos, provienen de la estructura llamada El Cuadrángulo, situada al final de la calle Norte-Sur. La cronología de esta amplia estructura, ubicada en un lugar privilegiado, se ha definido en varias unidades ubicadas en el perímetro del área cercada, en su interior, así como por la excavación de la entrada monumental (I-1/2016, Fig. 4). En todos los casos se ha determinado que el muro perimétrico fue construido en el Horizonte Tardío, parcialmente afectado por un terremoto, y luego, parcialmente reconstruido en el Periodo Colonial Temprano.

Entre los niveles con cerámica del Horizonte Tardío e Intermedio Temprano aparecen evidencias no registradas en los casos anteriores. Se trata de un nivel de uso funerario con entierros de la segunda mitad del Horizonte Medio (H-3/2013, J-5/2017, Fig. 5). Los fardos, ocasionalmente con máscara, están acompañados de cántaros y ollas Ychsma Inicial, así como de keros y tazones de estilos que Uhle (2003 [1903]) llamaba Epigonales (Eeckhout 2018). Llama la atención, notablemente, la diferencia en el espesor de los estratos correspondientes al Horizonte Tardío con respecto al delgado estrato que contiene materiales del Horizonte Medio (Fig. 6). Los entierros del Horizonte Medio corresponden a una de las agrupaciones funerarias, las que según Uhle (2003 [1903]) formaban parte de su Cementerio 1. 


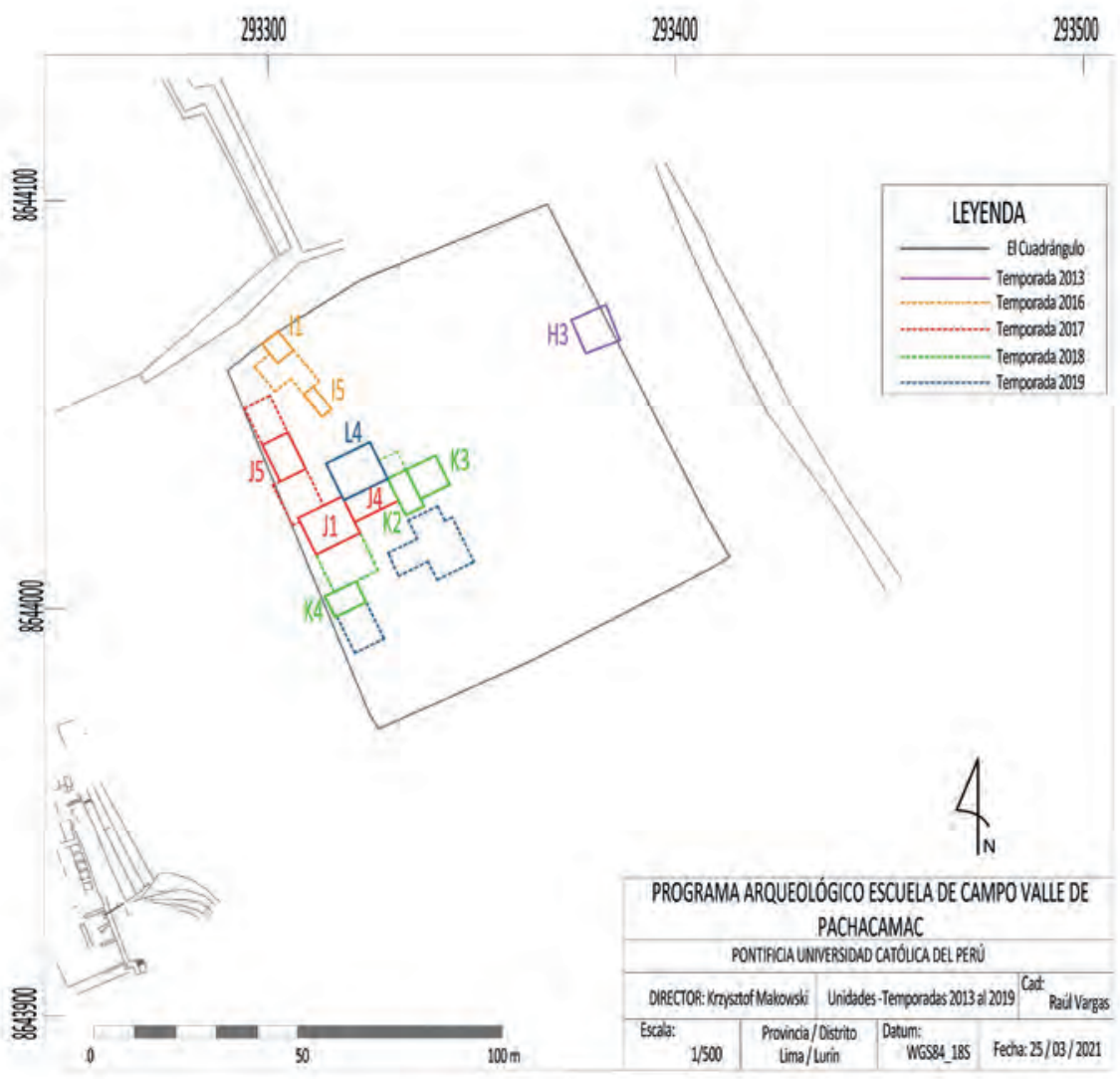

Figura 4. Plano de ubicación de las unidades de excavación mencionadas en el texto, dentro del perímetro de «El Cuadrángulo", desde 2013 hasta 2019 (dibujo: Raúl Vargas, PATL)

Figura 5. Contexto funerario \# 1 encontrado en la unidad J-5/2017; nótese la presencia de una máscara de cerámica, con ojos removibles, que tapaba el rostro, en asociación con un vaso - kero de estilo Epigonal, según la terminologia de Uhle (2003[1903]) (fotografía: equipo PATL).

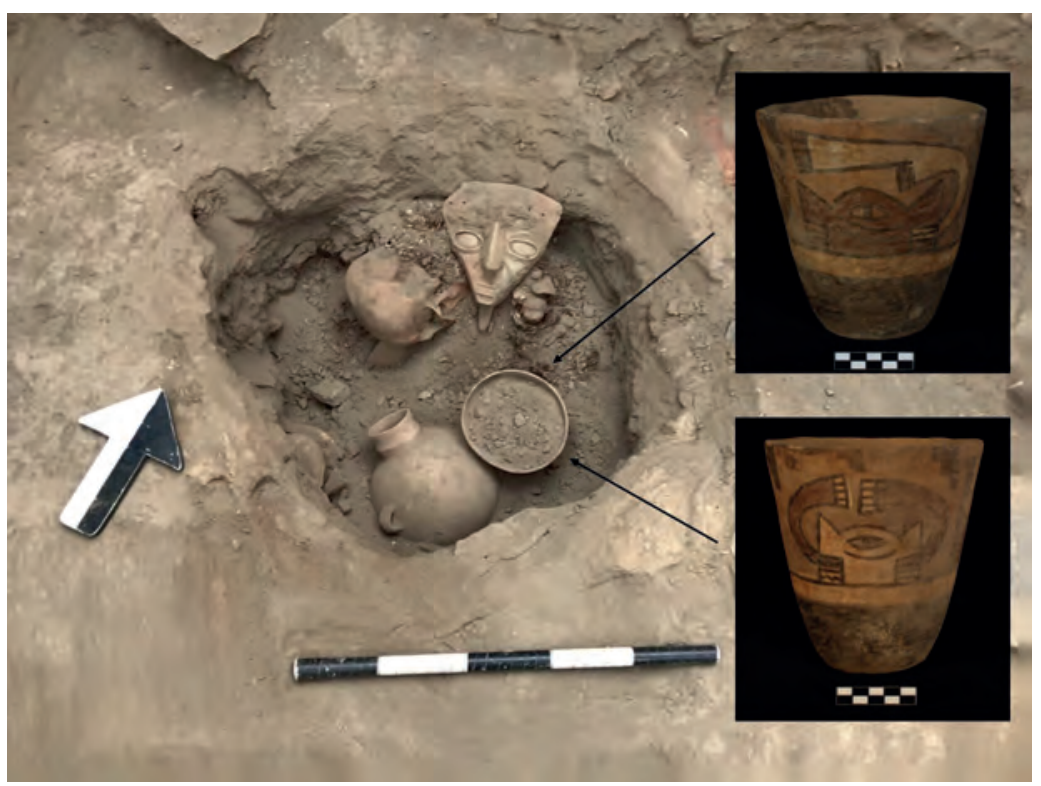




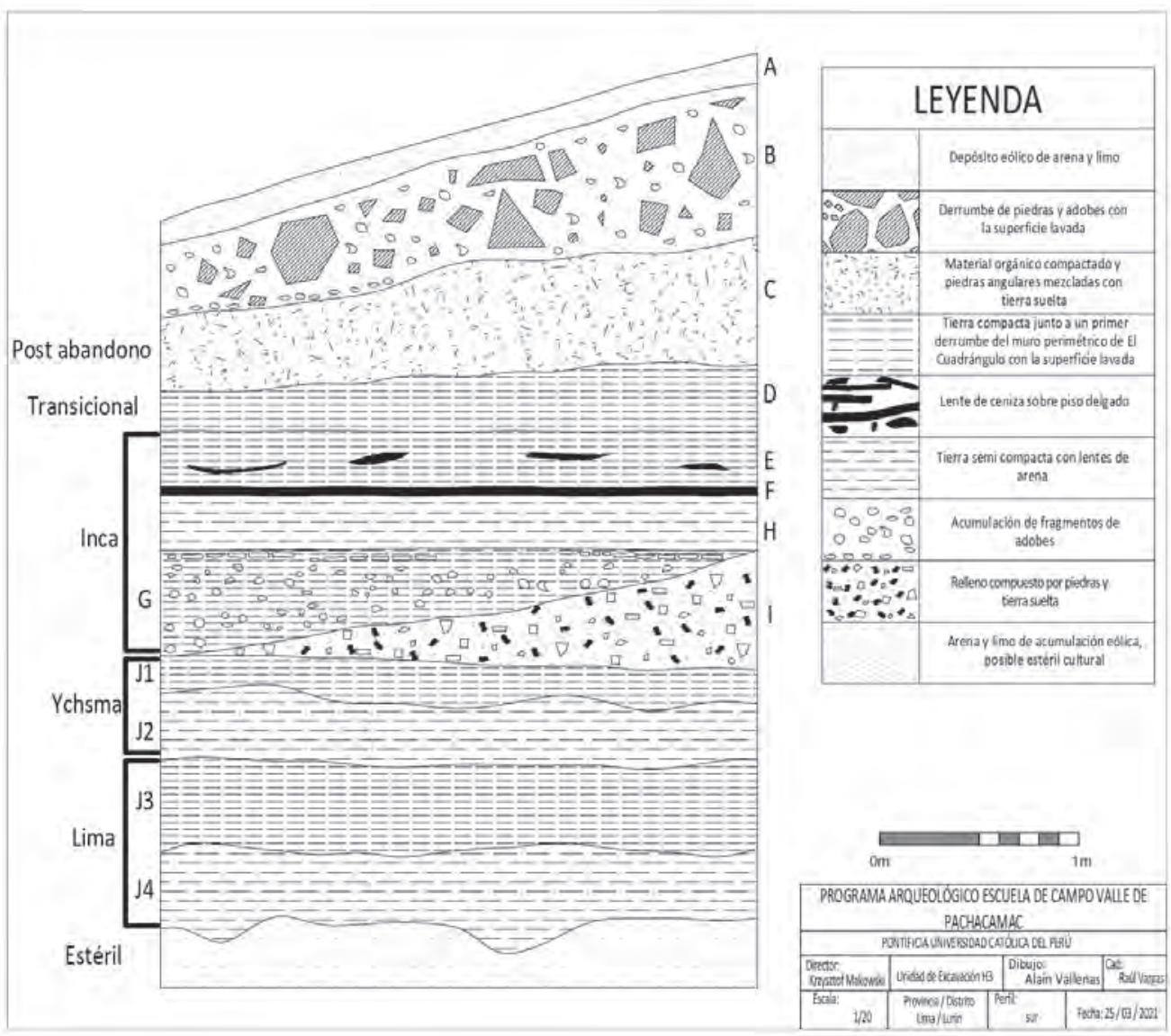

Figura 6. Dibujo del perfil sur de la unidad de excavación H-3/2013, perpendicular al muro perimétrico este de El Cuadrángulo; el muro está asentado en la capa H. Nótese que el espesor de los estratos guarda proporción con la intensidad de las actividades y eventos constructivos: Periodo Horizonte Tardio y Colonial Temprano, niveles D-I; Periodo Horizonte Medio 2B-4 - Intermedio Tardío, niveles J-1, J-2, Periodo Intermedio Temprano (Lima), niveles J-3, J-4 (dibujo: Raúl Vargas, PATL).

La historia ocupacional del área de El Cuadrángulo resultó ser mucho más compleja a la luz de los resultados de nuestras excavaciones del complejo arquitectónico, tanto en la entrada al recinto, como en la parte central elevada.

La secuencia corresponde a siete diferentes periodos de ocupación sobrepuestos, en el área del muro perimétrico de El Cuadrángulo, los que están enumerados en la Tabla 2.

Los niveles de ocupación Lima fueron definidos, en primera instancia, a través de un sondeo estratigráfico (Fig. 7) realizado en el eje del acceso a El Cuadrángulo. Este acceso tiene la forma de una portada-vestíbulo, se encuentra seguida por un callejón empedrado interno, con terrazas y banquetas en ambos lados, así como por un pequeño torreón de vigilancia en la esquina del edificio. Este último era accesible por medio de una rampa.

El sondeo puso en evidencia que ni el callejón ni el empedrado inca, en uso durante el Periodo Colonial Temprano, continuaban hacia el Sur. Debajo del relleno de nivelación inca encontramos arquitectura previa Ychsma y luego, casi cinco metros de compleja estratigrafía. Los estratos Lima Medio con cerámica Interlocking (Lima 4, 5 de Patterson 1996) se acumulan sobre el nivel estéril 
1 Áreas de actividad con arquitectura Lima Medio

2 Áreas habitacionales y funerarias del Periodo Horizonte Medio 2, 3, 4 (Ychsma Inicial y Huari: 900 - 1100 d.C.)

3 Áreas de banquete y entierros del Periodo Intermedio Tardío (Ychsma: 1100-1300 d.C.)

4 Hiato y breves episodios ocupacionales varios

5 Área de actividad con producción de chicha del Periodo Horizonte Tardío (1450 - 1530 d.C.)

6 Edificio de culto inca afectado por un terremoto y parcialmente reconstruido en la época del primer contacto con los españoles.

7 Reutilización del edificio como tambo en el Periodo Colonial Temprano (1533-1571 d.C.)

Tabla 2. Cuadro resumen de la secuencia ocupacional registrada en la parte central elevada en el área del perímetro de El Cuadrángulo
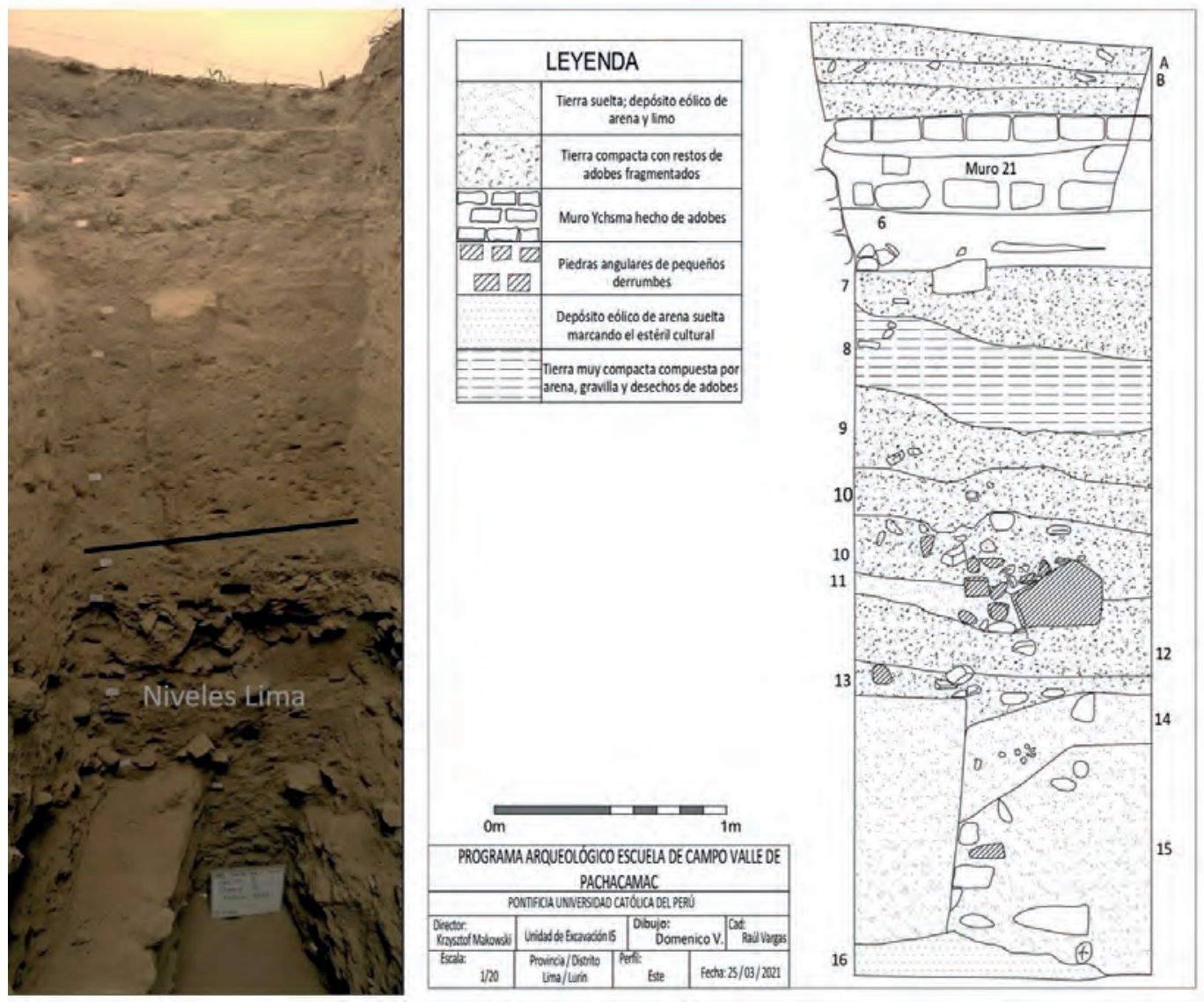

Figura 7. Perfil este del sondeo realizado en la proyección del eje de la calle Norte-Sur, en medio del pasadizo en construcción que interconecta el vestíbulo de la entrada a El Cuadrángulo con el interior de este gran recinto, unidad I-5/2016 (fotografía y dibujo: Raúl Vargas, PATL). 
con un espesor total de, aproximadamente, dos metros. En el estrato inferior solo se encontró cerámica Lima Marrón. La composición de capas con adobes y materiales constructivos hace pensar que la secuencia excavada se relaciona con la construcción progresiva del Templo Viejo, colindante al Sur.

Gracias al largo perfil suroeste-noreste (Figs. 8a y 8b) se puede evaluar en detalle la relación estratigráfica entre estos diferentes episodios de ocupación, así como definir los mecanismos de formación de los diferentes niveles y estratos (Tabla 3). Otro perfil perpendicular al precedente visualiza la relación entre los niveles de deposición natural y las capas culturales por un lado y la arquitectura, por el otro (Fig. 9).

En los niveles correspondientes a las ocupaciones del Horizonte Medio se aprecia, hacia el fondo de la trinchera excavada, la superposición de pisos, algunos de ellos asociados a cimientos compuestos de una a dos hileras de adobes. Los cimientos se cruzan, por lo general, bajo ángulo recto. Los estilos de cerámica predominantes son imitaciones de estilos ayacuchanos con la decoración figurativa y geométrica, en particular Huamanga (Ochatoma 2007; Cabrera y Ochatoma 2016) asociado a Ychsma Inicial (Bazán 1990), este último relacionado con formas para almacenar líquidos y sólidos, así como para cocinar (Fig. 10). La misma situación se observa en los contextos funerarios antes mencionados. La precariedad de las estructuras y de las áreas de quema, así como la delgada capa de arena eólica que las separa, sugieren que se trata de eventos relativamente cortos y repetidos para un periodo limitado de tiempo. La mayor parte del material proviene de hoyos en los que se descartó cerámica rota y materiales orgánicos como osamenta de camélidos, moluscos y mazorcas de maíz.

Las ocupaciones Ychsma del Periodo Intermedio Tardío aparecen sobrepuestas encima de las precedentes y son de similar carácter en vista de que comprenden estructuras con cimientos de una a tres hileras de adobes y pisos asociados, así como hoyos con basura descartada, la que se compone, en mayor proporción, de restos óseos de camélidos. En cambio, llama la atención la escasez de restos marinos. La primera impresión es que se trata de eventos de preparación y consumo de alimentos especiales, dentro de un marco festivo. Estos eventos se repiten utilizando el lugar de manera preferente, previa nivelación de los vestigios de una ocupación anterior de carácter similar.

Cuando la administración imperial inca mandó construir un muro encima de una gruesa capa de nivelación que cubría la arquitectura anterior, estas edificaciones llevaban abandonadas un buen tiempo y las coronas de los muros expuestos habrían sido seriamente afectadas por la intemperie, llegando a erosionarlas. Situación similar, en cuanto a la sobreposición de los niveles del Horizonte Tardío sobre los del Horizonte Medio, fue documentada al norte de El Cuadrángulo, en el área denominada «Sala Central» (Peralta 2021).

El muro mencionado arriba, el que formaba parte del proyecto inca de El Cuadrángulo estuvo pintado con diseńos figurativos sobre un fondo crema. La gama de colores y los diseños son los mismos que en el vecino Templo Pintado, atribuido al mismo Pachacamac. Este primer muro quedó muy dañado después de un fuerte sismo, probablemente el mismo que dejó sus huellas en la fachada oriental del Templo del Sol.

Parte de los adobes pintados provenientes de los tramos destruidos fueron reutilizados en la reconstrucción, y los fragmentos de enlucidos pintados, junto con adobes enteros, se encontraron dispersos, tanto frente a la estructura como en los derrumbes internos, $y$, asimismo, frente a la fachada del ingreso a El Cuadrángulo. Los tramos reconstruidos fueron enlucidos y pintados, pero esta vez, sin diseños figurativos.

Frente al muro reconstruido se realizaron cuatro ofrendas contenidas al interior de profundos hoyos tubulares que comprendían figurinas masculinas vestidas, elaboradas en metal y conchas de Spondylus princeps. Junto con las figurinas, también se encontraron llamas de metal y de Spondylus princeps. El hallazgo de una cuenta de vidrio, sellada debajo del piso asociado al muro inca de la 

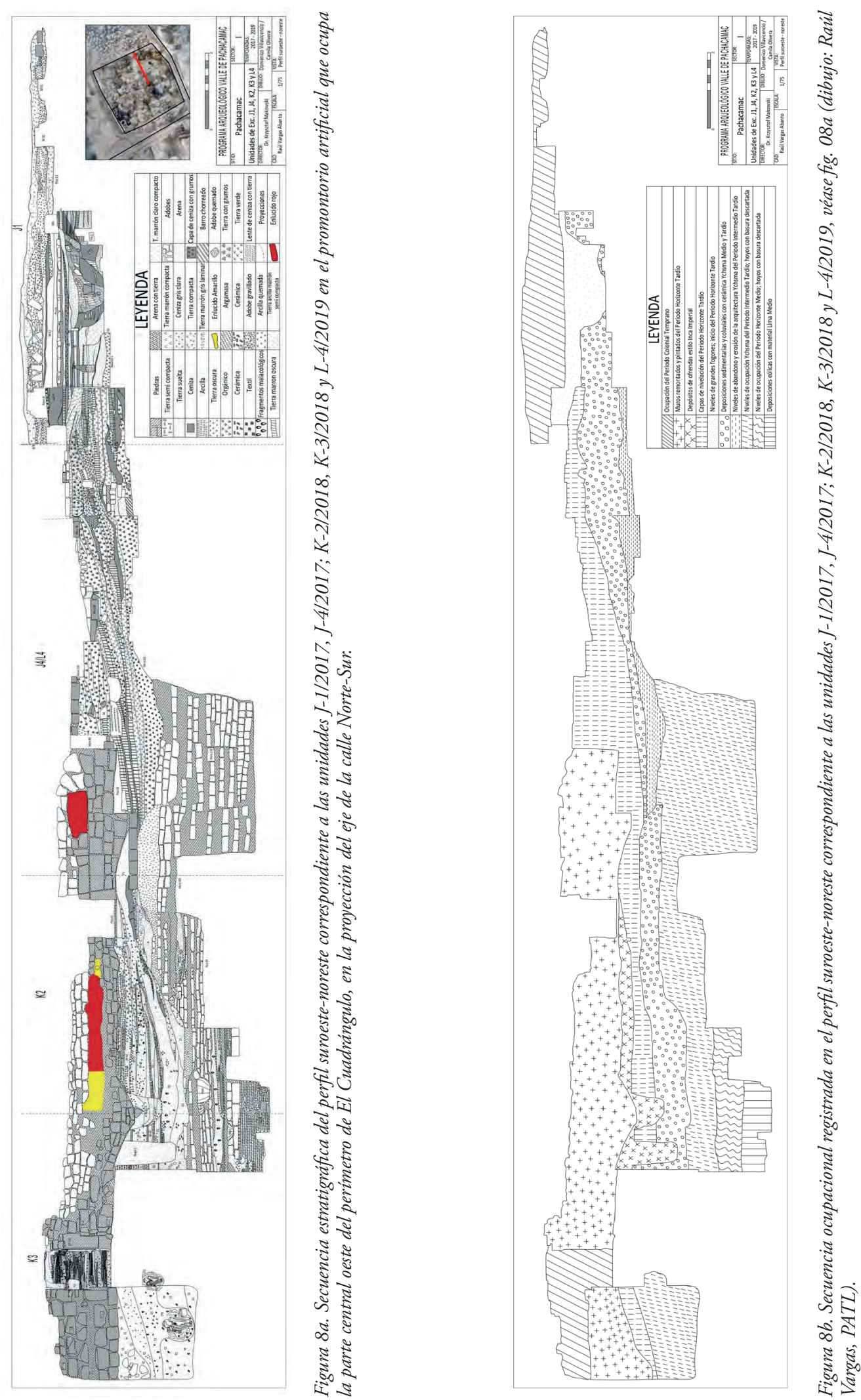


\section{Secuencia cronológica}

Ocupación del Periodo
Colonial Temprano

\section{Características de la secuencia deposicional}

Secuencia de pisos finos de ocupación doméstica sobre el terreno afirmado. Se registró una serie de remodelaciones en la ocupación colonial, tras su abandono se registró un gran derrumbe, de adobes y piedras de los muros coloniales, para finalmente terminar cubierto por sedimentos de deposición eólica.

Muros remontados y pintados del Periodo Horizonte Tardío
Después de la destrucción del muro 85 por un fuerte sismo, probablemente hacia 1512, se lleva a cabo la reconstrucción del muro inca reutilizando los adobes con pintura polícroma, con diseños al estilo del Templo Pintado, para erigir un nuevo muro en colores rojo y amarillo.
Depósitos de ofrendas estilo Inca imperial
La reconstrucción del muro 85 se vincula a un grupo de ofrendas del estilo cusqueño depositadas en pozos que cortan la primera nivelación Inca y los niveles de deposiciones sedimentarias del Periodo Intermedio Tardío.
Niveles de grandes fogones, inicio del Periodo Horizonte Tardío
Capas de nivelación del Periodo Horizonte Tardío
Existen tres niveles de quemas sucesivas pertenecientes a la posible producción de chicha en el lugar. Cortan capas de nivelación y, entre los niveles de quema, se hallaron lentes semicompactos de arena.

Estos rellenos de nivelación cubren estructuras previas para construir el promontorio artificial en el centro oeste de El Cuadrángulo. Se trata de tierra compactada y grumos de adobes.

Deposiciones sedimentarias y coluviales Ychsma Medio y Tardío

Está compuesta por una serie de niveles de arena suelta de acumulación eólica depositada entre niveles afirmados o apisonados. Algunos de estos niveles presentan secciones compactadas por exposición a lluvias, encerrando elementos orgánicos entre los niveles de deposición.

Niveles de abandono y erosión de la arquitectura ychsma del Periodo Intermedio Tardío

Niveles de ocupación ychsma del Periodo Intermedio Tardío; hoyos con basura descartada

Niveles de ocupación del Periodo Horizonte Medio; hoyos con basura descartada

\section{Deposiciones eólicas con} material Lima Medio
Las cabeceras de los muros de la ocupación ychsma sufrieron de desgaste por erosión eólica, también por el lavado de las cabeceras y parte de los paramentos, creando una costra de arcilla producto de la constante exposición a lluvias.

A este período pertenecen plataformas de nivelación rellenas de tierra con gran cantidad de grumos de adobes producto de la remoción de capas y estructuras previas. En este nivel, en este perfil, destacan los pozos para el descarte de basura con grandes concentraciones de cerámica fragmentada.

En este nivel de la secuencia constructiva hay un momento de deposición de arena fina entre niveles de tierra suelta con desechos de adobes, sobre el cual se construyeron superficies compactas o apisonados; en esta serie de apisonados se hacen pozos para el descarte de basura.

Este nivel marca un periodo de tiempo en el que el transporte de arena del litoral cubrió la zona, creando un manto de arena de diferentes grosores en el terreno; posiblemente creando pequeñas dunas, un ejemplo de ello se excavó en el fondo de algunas unidades de excavación debajo de El Cuadrángulo.

Tabla 3. Cuadro de la secuencia deposicional y episodios ocupacionales asociados, registrados en el perfil suroestenoreste que corresponde a las unidades J-1/2017, J-4/2017, K-2/2018, K-3/2018 y L-4/2019 (véase figs. 8a y b). 


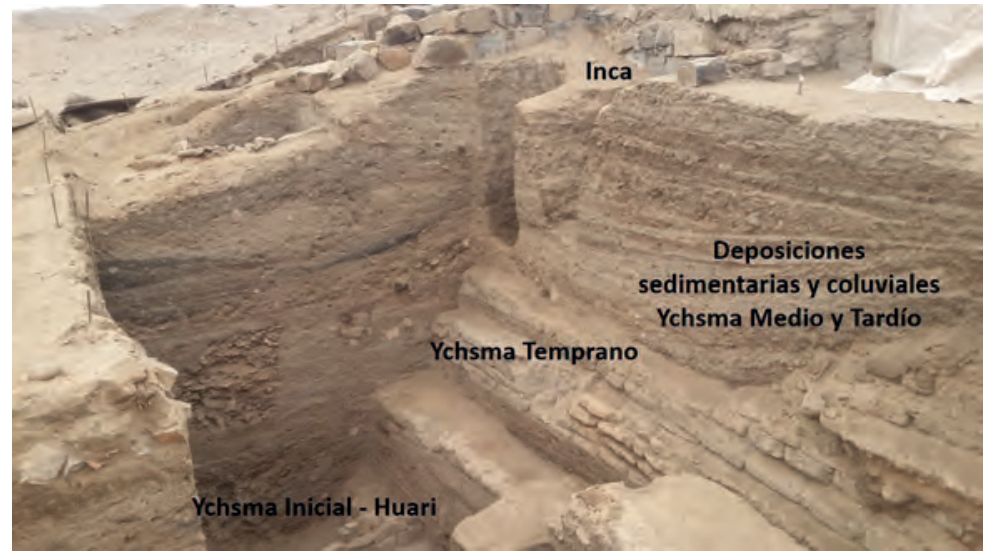

Figura 9. Esquina noroeste de la unidad K-3/2018, en donde se observa la relación entre los niveles de deposición natural y las capas culturales con la arquitectura del Horizonte Medio y del inicio del Periodo Intermedio Tardio, registradas en el perfil de las figs. 8 a y $b$ (fotografia: equipo PATL).

segunda fase, indica que la reconstrucción después del sismo tuvo lugar en un momento posterior al primer contacto con los espańoles, quizás el mismo descrito por Estete (1985 [1534]).

La situación estratigráfica que acabamos de comentar hace recordar, en varios aspectos, los famosos perfiles del Templo Pintado publicados por Uhle (2003 [1903]: 121-129, figs. 2-5). Recordemos que Uhle aprovechó un amplio forado que aún hoy se presenta en la fachada norte del Templo Pintado, cortando y perfilando sus paredes este y suroeste. En el corte de mayor extensión (Fig. 11) registró con gran precisión, tomando en cuenta la época, la relación estratigráfica entre los entierros de cámara, las capas que cubren y sellan la superficie de las áreas funerarias, llamadas por Uhle, el "cementerio 1»; por un lado, y las estructuras de piedra y adobe expuestas en el perfil, por el otro. Una plataforma recubierta de mampostería de piedra sin argamasa (Figs. $11 \mathrm{y}$ 12, letra «b»), construida desde el nivel de la capa de arcilla «de dos pies de espesor» (ibid.: 124) (Figs.11 y 12, letra «c») es la construcción de mayor antigüedad. Uhle (loc. cit.) la califica como «ruina antiquísima». Siguiendo a Uhle, al pie de la estructura se extiende «un estrato de adobe destrozado y de dimensiones irregulares, algunos adobes decorados de todos los lados» (loc. cit.) (Fig. 11, letra «d») que se depositó sobre la capa de arena (Fig. 11, letra «a»). Algunos entierros de cámara «tiahuanacoides» (Uhle 2003 [1903]: 122, 123, 129; fig. 3, letra «u») (Fig. 11, letra «u») se encuentran debajo de este estrato cortando la capa inferior de arena (Fig. 11 letra "a»), en el corte registrado. Las cámaras cilíndricas o cónicas de adobe y piedra estuvieron techadas con caña y esteras, raramente con piedra y contenían fardos orientados hacia el Este, «con una falsa cabeza humana superpuesta, cuyo rostro es de madera labrada o simplemente pintada, sobre un cojín relleno o a veces hecho de arcilla quemada y toscamente teńida» (Uhle 2003 [1903]: 133). No se conoce el registro detallado de estos hallazgos. Uhle consagra particular atención solo a uno de ellos (Uhle 2003 [1903]: 134-140, lám. 4, figs. 1,13,3, letra «u») que contenía una gran tela pintada, comparable desde el punto de vista iconográfico con los textiles de Castillo de Huarmey y Chimú Cápac. El textil estuvo asociado a cerámica de diversos estilos del Horizonte Medio 2B y 3, como Pachacamac y Nievería derivado, y una importación o imitación de cántaro escultórico de la costa norte (ibid., lám. 5; figs. 1, 9, 10, 11). Al pie de la plataforma revestida de piedra (Figs. 11 y 12, letra «b») y encima del estrato anterior (Fig. 11, letra «d»), se acumuló un gran derrumbe (Fig. 12, letra «e»), cortado por las matrices de los entierros «Epigonales» con cerámica Ychsma del Periodo Intermedio Tardío (Uhle 2003 [1903]: 122, 123, 129; fig. 3, letra «V»; 175-178) (Fig. 11, letra «V»). La misma plataforma está cubierta por otro derrumbe, marcado con la letra «g» (Figs. 11 y 12) 


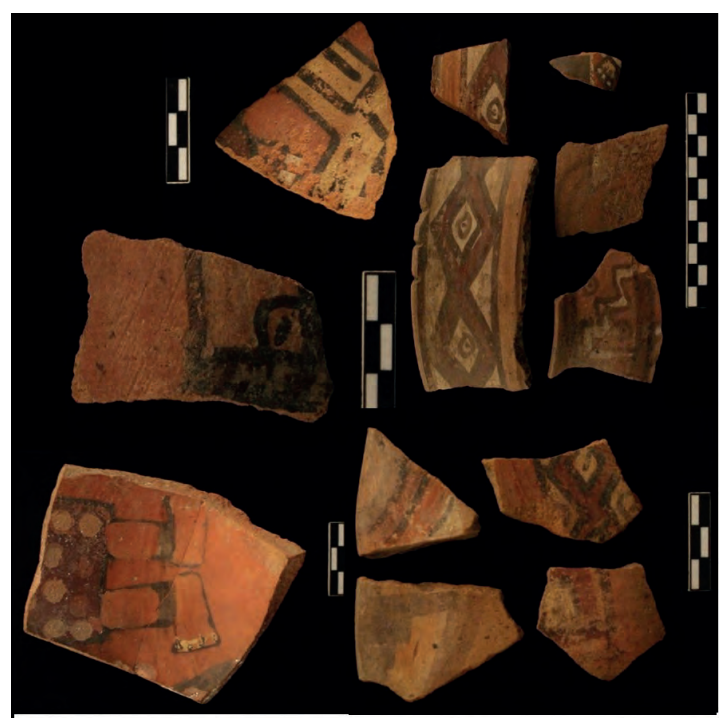

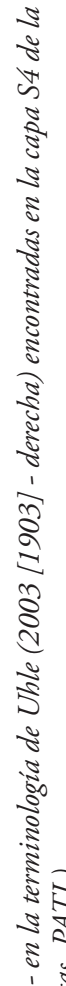
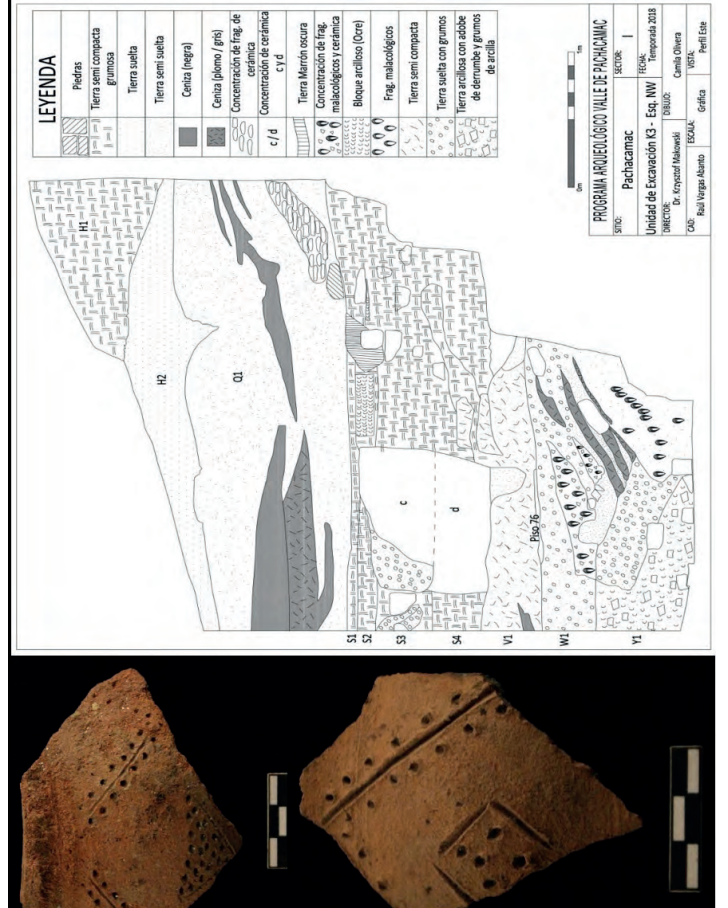

है

is

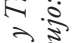

ฐี จิ

$\therefore 8$

बित

है

는

ริ :ี

2.

N.

त्ञ

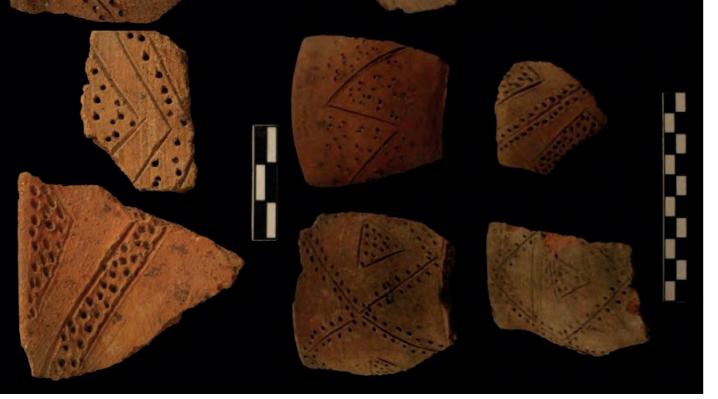

ปั

3

站弯

8

เ $\infty$

ปิ

过

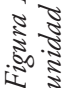




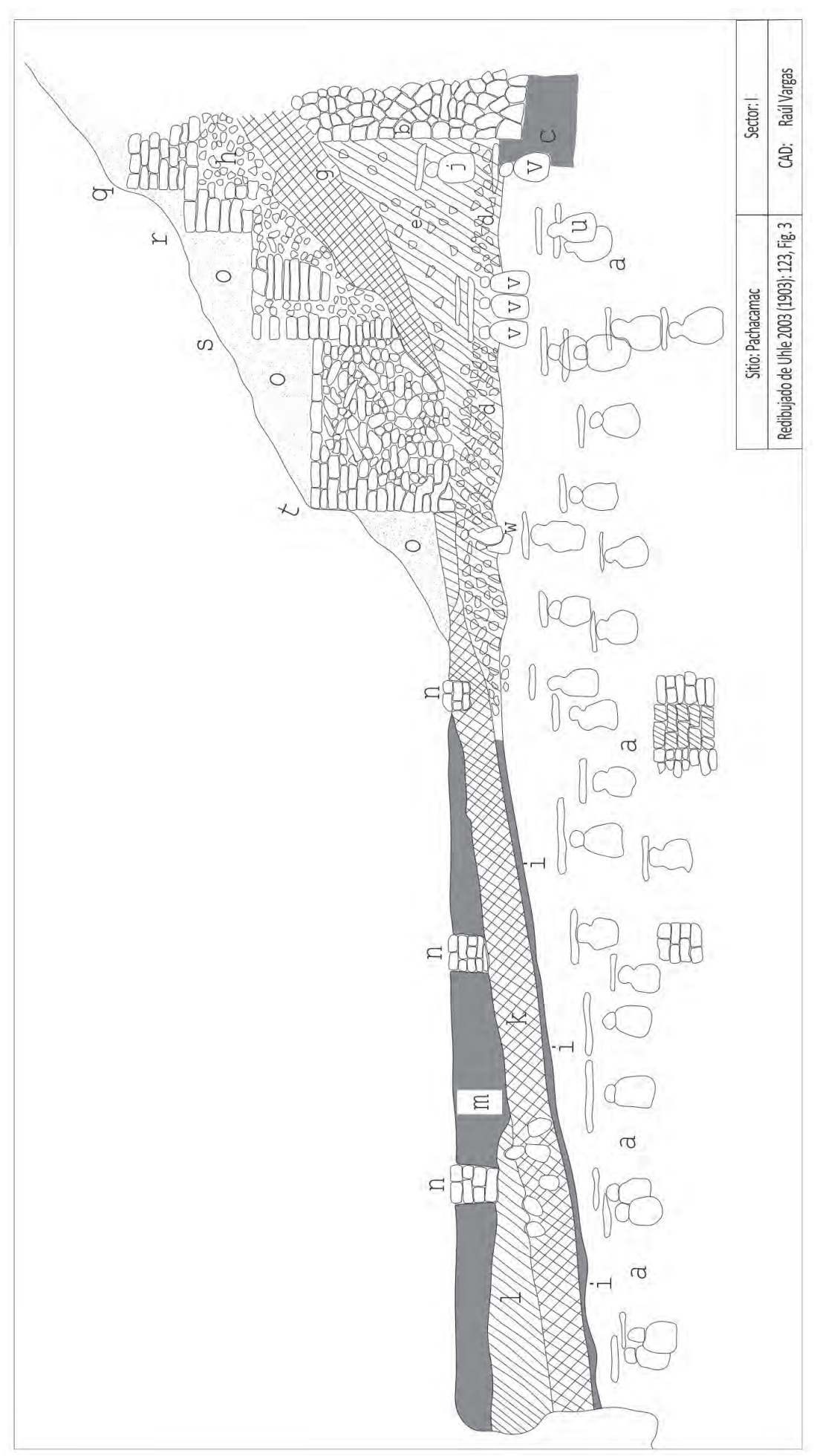

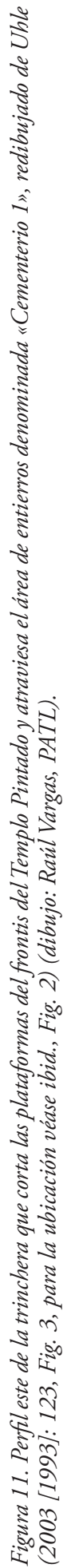




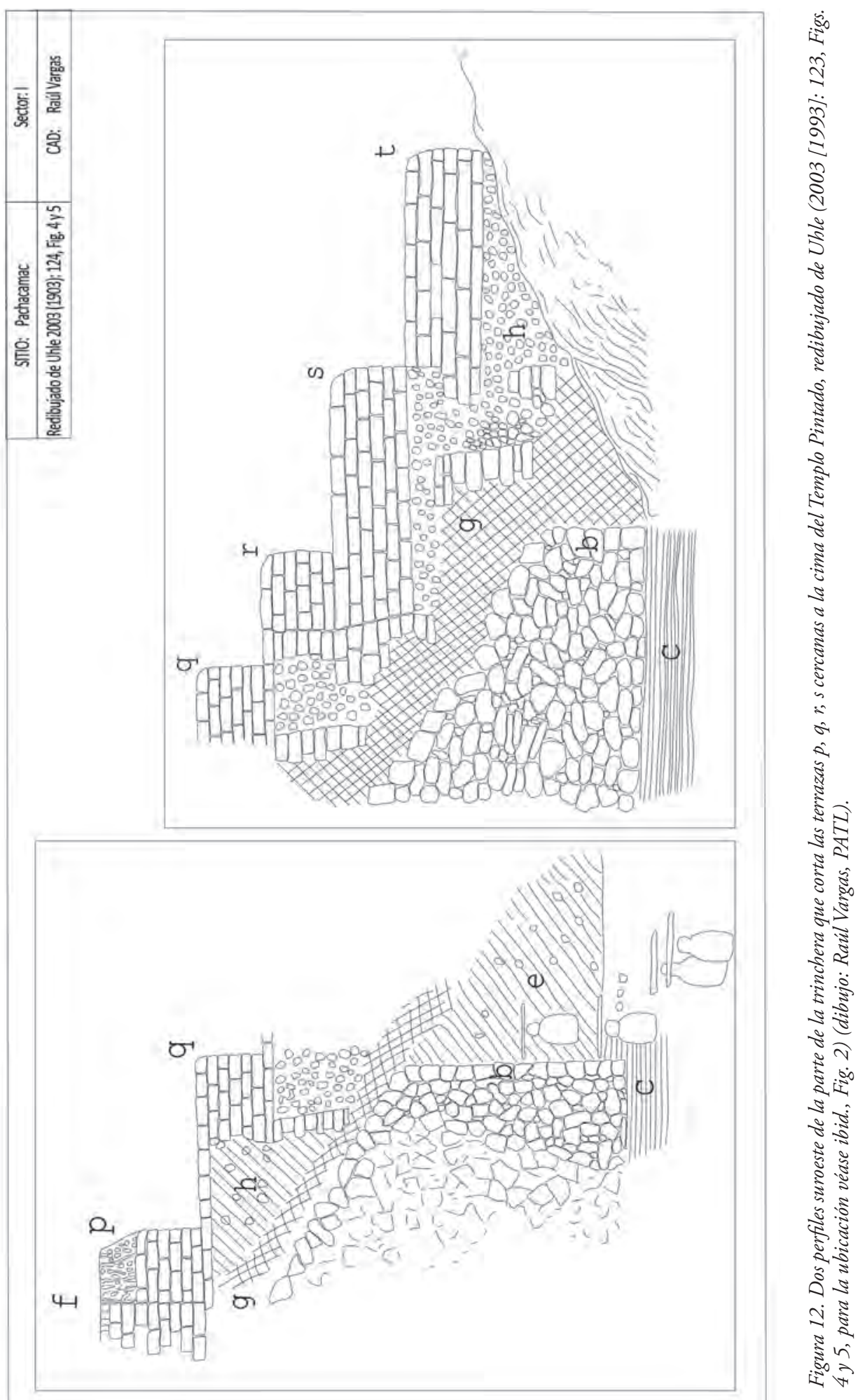


y que baja de las partes altas del promontorio del Templo Viejo, y está compuesto de «cascajo, lleno de fragmentos de todas clases; era un revoltijo de trozos de caña, huesos de llama, cráneos, trenzas de cabello humano, pedazos de soga de junco, jirones de tela, algunos fragmentos de alfarería tosca, etc.» (Uhle 2003 [1903]: 124-126). Recién, sobre este último derrumbe «g» se edifica, en dos fases constructivas, el Templo Pintado que, para Uhle, es estratigráficamente contemporáneo, a juzgar por los perfiles y la descripción, con los muros y entierros del Periodo Inca (Fig. 11, letra «W»).

Con la construcción del Templo Pintado se relacionan, en la descripción analítica de Uhle, los trabajos de nivelación en el frente del edificio. Sobre la superficie afirmada del área funeraria del Horizonte Medio y del Periodo Intermedio Tardío, marcada con la letra «i» (Fig. 11, letra «i»), una gruesa capa de cascajo fue extendida (Fig. 11, letra «k») y sobre ella se depositó una capa de hojas de Pacae (Inga feuilleei) - letra «l» (Fig. 11, letras «l»). Desde la superficie de estas dos capas de nivelación fueron construidos los muros este-oeste, marcados con la letra «n» (Fig. 11, letra «n»), aquellos que sostenían el relleno «m» (Fig. 11, letra «m»), conformando una amplia terraza en el frontis del templo (Uhle op. cit.:129). Desde este relleno, o desde el interfaz $\mathrm{m} / \mathrm{k}-\mathrm{l}$ se cavaron fosas que contenían entierros «marcados por objetos de tipo cuzqueńo» y que estuvieron marcados con la letra «w» (ibid.: 122, 123, 129, fig. 3).

Con los resultados que acabamos de exponer y contrastándolos con la documentación de Uhle (2003 [1993]), estamos cada vez más convencidos de que el Templo Pintado fue construido por la administración inca, pero usando mano de obra especializada de origen Ychsma. Ambas fases de construcción de este edificio y múltiples renovaciones de la decoración parietal polícroma (Bonavía 1974: 113-126, figs. 59-67; 1985: 135-147, figs. 98-109) parecen corresponder al Periodo Horizonte Tardío. Conforme con la documentación gráfica y descriptiva de Uhle (2003 [1903]), el Templo Pintado habría sido construido sobre las estructuras de periodos previos, que ya estaban abandonadas, en ruinas y cubiertas de escombros cuando se empezó con su edificación. Bonavía (1974), con razón, observa que las pinturas siguen los cánones del Periodo Intermedio Tardío (Ychsma), pero no duda en asignar cronológicamente la decoración del templo al Periodo Horizonte Tardío.

A los autores de este artículo les parece probable, que los pisos con postes empotrados, excavados, respectivamente, por Muelle y Wells (1939) y luego por Franco y Paredes (1985) en un amplio sondeo localizado en la plataforma de la cima, se relacionan con los vestigios de la arquitectura previa, arriba mencionados, y, por lo tanto, carecen de relación con la estructura inca, hipotéticamente dedicada al culto de dios Pachacamac, la que fue construida más de 600 años después. A este mismo edificio del Horizonte Medio pudieron haber pertenecido el ídolo bifronte de Pachacamac, encontrado por Giesecke (1938) en posición echada en diagonal y cubierto de escombros durante las excavaciones de la fachada del Templo Pintado (Dulanto 2001); y los pisos con postes conservados in situ y localizados dentro de sondeos realizados en la cima del edificio escalonado.

La comparación entre las descripciones de Uhle y la estratigrafía registrada en el vecino Cuadrángulo sugiere que la administración inca mandó a hacer trabajos de nivelación a gran escala en esta parte de Pachacamac. De este modo, las ruinas de estructuras construidas en el transcurso de la segunda mitad del Horizonte Medio y de las primeras fases del Periodo Intermedio Tardío (aprox. 800-1100 d.C.) quedaron no solo cubiertos de gruesos rellenos, sino, encapsulados mediante muros de contención.

De este modo, se creó una configuración estratigráfica que pudo resultar de difícil lectura. Los arqueólogos que excavaron sondeos en la cima del volumen de Templo Pintado (Franco y Paredes 1985) aparentemente encontraron niveles correspondientes al periodo Epigonal de Uhle (Horizonte Medio 2B-3-4) relativamente cerca de la superficie. Esto ha creado una apariencia de contemporaneidad de los pisos encontrados con las paredes policromadas, en la que se sustenta la hipótesis de que el Templo Pintado fue construido para el dios Pachacamac en la época Wari 
y desde aquel entonces, hasta la conquista española, haya permanecido en uso ininterrumpido. Se debe recordar que, tanto el ídolo como las bases de postes, cuentan con fechas C-14 (calib.) correspondientes a los siglos VIII/IX d.C. (Dulanto 2001; Sepúlveda et al. 2020). Algunos de los fechados mencionados (Franco y Paredes 1985; Paredes 1985; Franco 2004) sugieren la existencia de dos fases sobrepuestas y continuas en la historia del Templo Pintado, la fase Roja (Horizonte Medio 2, 650-750 d.C.) y la fase del Templo Policromado (Horizonte Medio 3 hasta el Horizonte Tardío, 750-1533 d.C.). Los autores esperan haber demostrado que esta última propuesta cronológica no solo carece de fundamentos estratigráficos, sino, que entra en clara contradicción con las evidencias registradas y discutidas por Uhle (2003 [1903]).

Volviendo al recinto denominado El Cuadrángulo, tal como lo hemos anunciado al principio, la historia ocupacional y deposicional del montículo artificial que se ha formado en la parte central de la mitad occidental del recinto no termina en 1531/1532. Se puede apreciar esta situación en la portada y en el callejón de la entrada, así como en la parte más elevada del montículo que está adyacente al muro perimetral oeste de El Cuadrángulo (Fig. 13). En esta última zona, en las capas superficiales, hemos descubierto una alargada estructura rectangular con un corredor central y varios ambientes abiertos y techados en ambos lados. La estructura posee muros de adobes reutilizados, de tamaño variado, y cimientos.

El edificio es accesible desde el Norte, en el eje de la puerta principal de El Cuadrángulo. Al final del corredor se accede a un aposento especial que cuenta, entre otros, con una especie de balcón techado con una banqueta. Dicho balcón se abre a través del muro perimetral occidental, desmontado hasta el nivel del piso del aposento para crear una especie de amplio ventanal, ofreciendo una vista a la entrada del Templo Pintado. La plataforma del balcón está parcialmente destruida a raíz de un derrumbe que afectó una parte del ventanal. A la estructura colonial temprana se asocian amplias áreas de actividades y almacenamiento. Estas están comprendidas, entre otros, por recintos rectangulares alineados a lo largo del muro perimetral oeste, y por acondicionamientos diversos entre los que encontramos fogones y depósitos menores al este de la estructura principal.

El material cerámico, estadísticamente predominante en los niveles mencionados, es Ychsma Tardío con presencia minoritaria, pero significativa, de estilos diagnósticos del Periodo Horizonte Tardío, en particular, Chimú-Inca y Cuzco Polícromo. Estos estilos están, en particular, presentes en las ofrendas.

Si no fuese por el método de excavación por decapado y el uso ocasional de zarandas finas no nos hubiéramos percatado, quizás, de que estas evidencias están directamente asociadas con los artefactos de procedencia europea, como cuentas de vidrio. Solo en algunos lugares, como en el pasadizo, se encontraron también clavos de fierro, fragmentos de clavos de herraduras, cuero, fieltro y bosta de caballo. No hay, en cambio, ni un solo fragmento de cerámica vidriada. La ocupación colonial es muy dinámica, con presencia de varios pisos y algunas remodelaciones. El encomendero a cargo de lo que parece haber sido el primer tambo español en uso en la zona - por lo menos hasta la construcción de la reducción de San Salvador de Pachacamac ${ }^{1}$ en 1572 —, mandó a reconstruir las partes destruidas por el terremoto que afectó El Cuadrángulo inca, poco antes de la llegada de los españoles y ordenó, cubrir la arquitectura previa con varios rellenos, estabilizados con parrilla de muros de contención, y luego nivelados.

La presencia de material de origen peninsular es reportada, por lo general, de manera muy escueta en excavaciones en otras zonas de Pachacamac. La excepción la constituyen las recientes evidencias encontradas en el edificio B4 (Praet et al. 2017) ubicado a poca distancia y al este de El Cuadrángulo. En opinión de los investigadores citados, el pequeńo edificio dedicado a rituales durante el Horizonte Tardío se transformó en un establo, ubicado dentro de un ambiente doméstico, con la llegada de los españoles. 


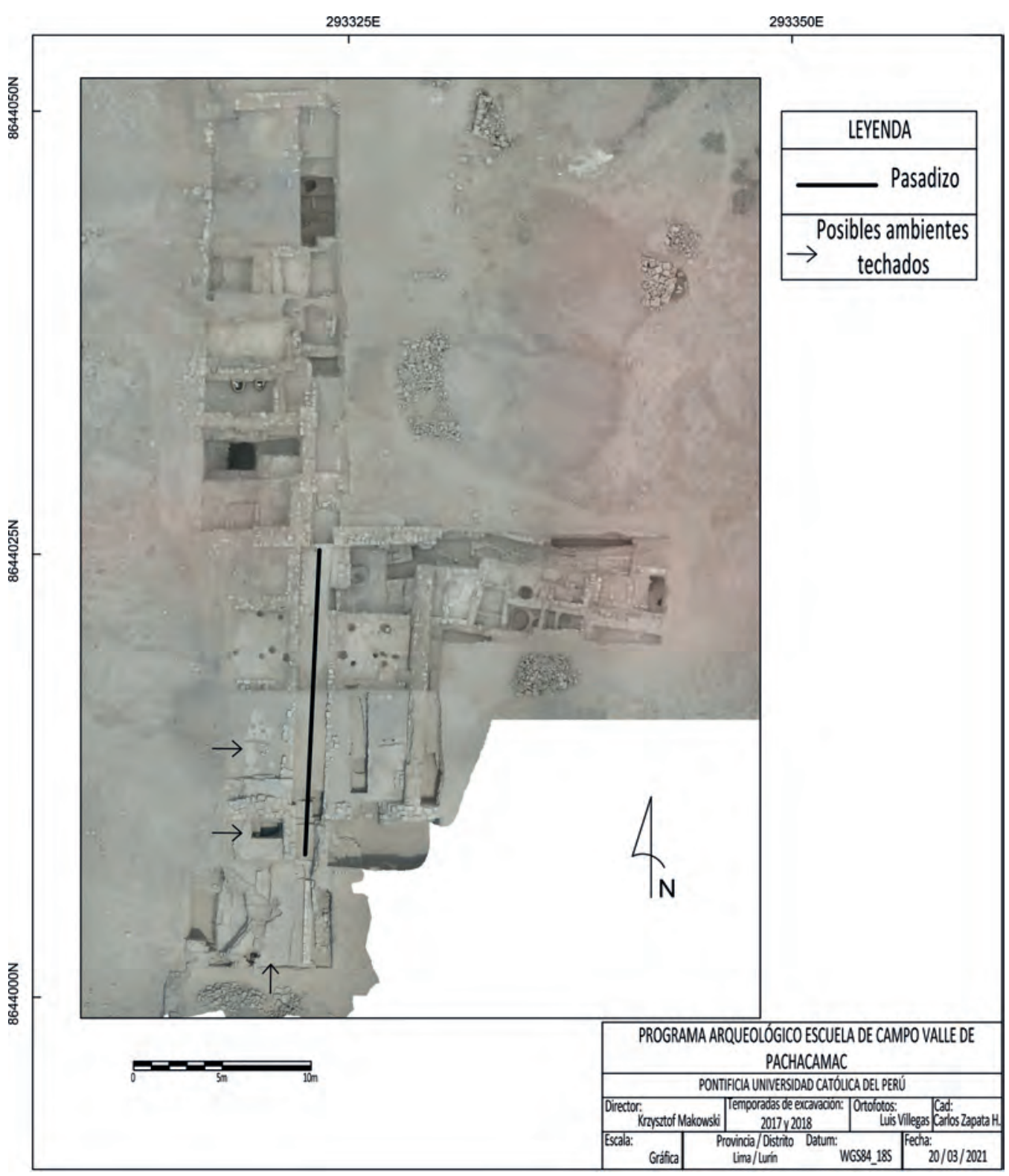

Figura 13. Ortofotomapa de las unidades excavadas durante las temporadas 2017 y 2018 en El Cuadrángulo: en la parte norte nótese depósitos y recintos para la preparación de alimentos y bebidas adosadas al muro perimétrico; en la parte sur está expuesta la estructura colonial temprana, con el largo pasadizo central, así como ambientes techados y abiertos de ambos lados (ortofotomapa: Carlos Zapata, PATL). 


\section{Factores naturales de impacto en la estratigrafía de Pachacamac}

El santuario de Pachacamac se encuentra en un lugar estratégico entre la desembocadura del río Lurín, el cual forma un delta poco pronunciado al llegar al océano Pacífico, y albuferas entre el santuario y el mar, en medio del desértico litoral limeńo. El relieve del área es el fruto de sucesivos ciclos orogénicos, comprendiendo en ellos varias etapas de sedimentación, de deformación, levantamientos y finalmente, de erosión y peneplanización ${ }^{2}$ (INGEMMET 1995). Estudios realizados en el litoral del departamento de Lima muestran el régimen tectónico de tipo extensional del cuaternario (Macharé 1981; Macharé et al. 1986; Jacay y Oshiro 2015), con un relleno sedimentario propio de deltas fluvio-aluviales, para la formación de las grandes pampas costaneras asociadas a depósitos de abanicos coluviales de corto recorrido. Estos últimos están presentes en las numerosas quebradas cortas y coalescentes a los ríos de la costa.

El sitio de Pachacamac se encuentra próximo a las lomas de Atocongo, Tablada de Lurín y Lúcumo, así como a los Pantanos de Villa. Estos son focos de humedad, los cuales debieron estar vinculados, en el pasado, con las albuferas de la laguna Urpiwachak (Winsborough et al. 2012). Los factores importantes que debemos de tener en cuenta en la formación de niveles deposicionales son, por un lado, la concurrencia cíclica del fenómeno de El Niño que ocurre en un régimen de años predecible (Macharé y Ortlieb 1993), pero con variaciones en su magnitud y zona de devastación (Sandweiss y Quilter 2012); y, por el otro, los eventos sísmicos ocurridos por la subducción de la placa de Nazca y la placa continental, lo que genera eventos catastróficos como los registrados históricamente en 1586 y 1687.

Como ya hemos mencionado en párrafos anteriores, la actual configuración visual del Santuario es el resultado de la superposición y del crecimiento horizontal de la arquitectura prehispánica durante, aproximadamente, mil años, desde el Periodo Intermedio Temprano, variando las características de arquitectura y de su organización espacial de periodo en periodo. No obstante, los eventos naturales también han jugado, y lo siguen haciendo, un papel importante para la configuración y la formación de capas estratigráficas. En Pachacamac, se han encontrado evidencias de los eventos medioambientales de tipo mega Niño y, también, de sismos de gran magnitud y posibles tsunamis, tanto en el registro arqueológico de la zona, como en el estudio medioambiental realizado en la laguna Urpiwachaq (de los Patos, Winsborough et al. 2012).

Durante, aproximadamente, los 1700 ańos que han transcurrido desde el inicio de los trabajos constructivos en Pachacamac, en el Periodo Intermedio Temprano, hasta el presente, varios eventos sísmicos debieron haber afectado a las estructuras de adobe. La mayoría de ellos no fueron ni percibidos ni mucho menos registrados por los investigadores. El interés de los arqueólogos se ha centrado en el gran sismo de Lima de 1746 (Pozzi-Escot et al. 2017).

Las excavaciones realizadas por Makowski y colaboradores han puesto en evidencia otro evento sísmico de gran intensidad que tuvo lugar poco antes de la llegada de los españoles a Pachacamac, en el Periodo Horizonte Tardío. Las huellas del terremoto, muros derrumbados y luego parcial o totalmente reconstruidos, $y$, en algunos casos, por el contrario, desmontados hasta los cimientos, posiblemente para volver a usar los adobes y piedras del revestimiento, fueron encontrados casi en todas las unidades excavadas, en particular, en la calle Norte-Sur (Makowski 2008), en El Cuadrángulo (Makowski 2017, 2019) y en el vestíbulo de la entrada principal al Templo del Sol (Makowski 2013). Es probable que se trate del mismo sismo registrado, también, en el sector II de Pueblo Viejo-Pucará, donde varios recintos residenciales afectados y en ruinas fueron cubiertos con rellenos para volver a construir una estructura nueva sobre ellos (Makowski 2008; Makowski et al. 2008).

Los efectos de las lluvias fuertes, siempre excepcionales en la costa central, algunos de ellos relacionables con el fenómeno ENSO, dejaron también huellas tangibles registradas en capas limo arcillosas laminares encontradas junto a restos culturales en diferentes periodos de ocupación y en 
diversas partes del Santuario (Makowski 2009, 2013). De otro lado, también Franco y Paredes (2016) registraron en la cima del Templo Viejo eventos de desgaste de muros y deposición de sedimentos, producto de eventos de fuertes lluvias, durante la excavación de recintos con ofrendas.

En El Cuadrángulo, se han encontrado contundentes evidencias de lluvias torrenciales que crearon correntías y gruesos depósitos laminares sobre los pisos de los pasadizos y rellenando depresiones. Las coronas de muros perimétricos quedaron también afectadas. Los eventos de lluvias parecen haberse repetido en los ańos que precedieron al abandono definitivo de la zona y algunos de ellos coinciden cronológicamente con el saqueo generalizado de entierros humanos. Se puede ver, por ejemplo, un manto abandonado y procedente de un fardo disturbado que se extiende entre las capas de barro laminar en la entrada a El Cuadrángulo en niveles correspondientes al Periodo Colonial Temprano. Estos eventos anteceden a la búsqueda desenfrenada de objetos de valor mediante grandes forados. Dichos forados destruyeron parcialmente la arquitectura colonial, junto con sus antecedentes inca e ychsma.

La estratigrafía de la entrada principal, y probablemente la única, de El Cuadrángulo, excavada en el 2016, proporcionó evidencias para correlacionar lluvias anormales, repetidas, con la presencia española, y, asimismo, para registrar efectos destructivos de un sismo de considerable magnitud, seguidos por intentos de reconstrucción parcial de la arquitectura afectada, en tiempos del primer contacto con los españoles.

La entrada posee una calzada que asciende mediante una serie de anchas gradas inclinadas del Norte al Sur; es decir, desde la plaza hundida al final de la calle Norte-Sur, donde una rampa permite el acceso a la portada de El Cuadrángulo. Toda la superficie de la calzada se encuentra recubierta por estratos laminares sedimentarios y surcada por pequeñas correntías. Dos sondeos en los dos extremos de la calzada, en la entrada y en el extremo meridional donde el empedrado desaparece, revelaron la secuencia de eventos previos a la construcción de la calzada.

En el sondeo meridional se pudo comprobar que la vía estuvo en construcción en esta parte, y que se estaba preparando el terreno por medio de una gruesa capa de rellenos que cubrían la arquitectura de adobes, parcialmente destruida, del Periodo Intermedio Tardío. Los rellenos contienen material cerámico diagnóstico del Periodo Horizonte Tardío. La construcción fue abortada, posiblemente relacionada con el terremoto que provocó la considerable destrucción de los muros laterales y terrazas que bordeaban la vía y formaban parte del complejo monumental de la entrada. Esta arquitectura fue parcialmente reconstruida y adaptada para nuevos fines al inicio del Periodo Colonial. En el sondeo debajo de la calzada de la entrada llama la atención la presencia de una gruesa capa de derrumbe, la que contiene dos capas delgadas que la cubren, posiblemente con un fin de nivelación, y fragmentos de adobes con policromía figurativa. Los diseños y colores son comparables con la pintura mural en la fachada escalonada del Templo Pintado de Pachacamac.

El derrumbe mencionado en el párrafo anterior lleva a pensar que, en la fase de construcción que antecedía a la actualmente conservada, el muro perimétrico de El Cuadrángulo, por lo menos en la parte frontal, debió contar con decoración figurativa pintada. No obstante, los muros que conservaron parte de sus paramentos intactos solo presentaron enlucidos llanos de color amarillo parduzco (Munsell 10YR 6/8 brownish yellow), como todas las estructuras del Periodo Colonial, expuestas en nuestras excavaciones desde el 2016 hasta la fecha.

La situación observada en el complejo de la entrada a El Cuadrángulo se repite en el caso de un recinto de adobes (Fig. 14, muro 85) construido encima del montículo artificial, cuya compleja estratigrafía preinca se ha analizado páginas atrás. La puerta que da al interior del recinto mencionado se encuentra al final del eje Norte-Sur, la que se puede trazar siguiendo el recorrido de la calle amurallada hasta el ingreso a El Cuadrángulo.

Durante las temporadas 2017 y 2018 hemos constatado que los muros de este recinto estuvieron originalmente decorados con policromía figurativa, similar a la del Templo Pintado. La decoración se ha conservado in situ en la esquina interna sureste (muros 161 y 202). Hemos 


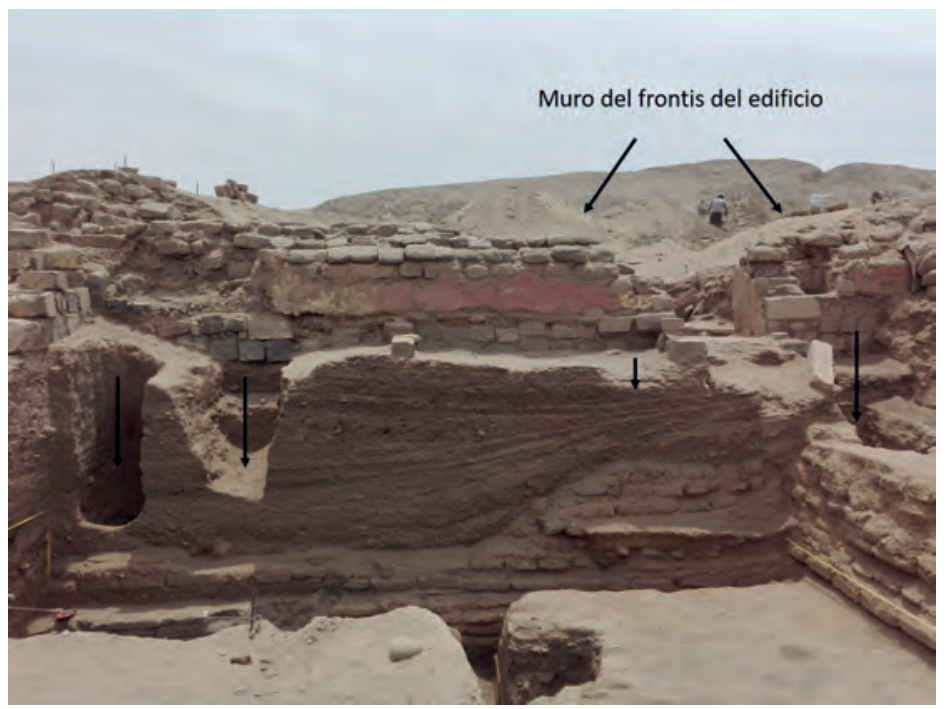

Figura 14. Muro del frontis del edificio del Horizonte Tardio localizado en el eje de la calle Norte-Sur, en la cima del promontorio artificial ubicado en la parte central del perimetro de El Cuadrángulo. El muro tuvo policromía figurativa en su primera fase antes del terremoto de 1512 y reconstruido después, fue pintado de color rojo y amarillo. También se observan los pozos en donde se encontraron las ofrendas de estilo inca imperial (fotografia: equipo PATL).

comprobado, asimismo, que otros segmentos del recinto fueron remontados reutilizando cientos de adobes decorados con pintura figurativa. Los muros reconstruidos recibieron enlucidos con pintura de color rojo. Una incisión circular pintada en amarillo se conservó, también, cerca de la puerta de acceso al recinto, en la cara externa. El contenido de cuatro profundos hoyos, cavados a lo largo de la parte frontal del muro en el nivel correspondiente a su segunda fase, no deja lugar a duda de que la reconstrucción del edificio, después de terremoto, fue emprendida por la administración inca, dado que se trata de ofrendas de estilo imperial, como la que fue depositada en la cima del Templo Viejo (Franco y Paredes 2016; Makowski y Vargas 2019). Componentes similares —estatuillas vestidas de ropa miniatura, figurinas de llamas —acompañan; por ejemplo, los sacrificios de niños (Capacocha). No obstante, el hallazgo de una cuenta de vidrio en el estrato de nivelación debajo del piso de la entrada indica que los trabajos de reconstrucción fueron emprendidos después del primer contacto con los españoles. Cabe recordar que Hernando Pizarro llegó a Pachacamac en enero de 1533 (Estete 1968 [1536]; Pizarro 1968 [1533]).

Estete (1968 [1536]) describe que mientras se encontraban en el pueblo de Pachacamac, antes de poder ingresar al Santuario, hubo un fuerte temblor que espantó a los indios que se encontraban siguiéndolos. Este temblor no debió significar una destrucción importante de las estructuras de esta parte del Santuario; puesto que, Estete describe su ingreso sin mencionar escombros o posibles obstáculos que evitaran el acceso a la parte ceremonial del Santuario. El mismo cronista afirma, al igual que Hernando Pizarro (1968 [1533]), que los españoles destruyeron «la cueva del demonio» en busca de bienes de oro y plata. No hemos encontrado evidencias de este saqueo en los niveles previos a la ocupación colonial permanente de El Cuadrángulo que podrían corresponder al episodio de primer contacto. Las construcciones en esta zona han sido, en cambio, muy dañadas por un sismo de particular intensidad, anterior a la llegada de los españoles. En las fuentes (Esquivel y Navia 1901 [1740]; Garcilaso de la Vega 1985 [1609]: 392-393) se menciona un terremoto con tsunami y múltiples deslizamientos de tierra, que habría acontecido durante el gobierno de Huayna Cápac, hacia 1512, y cuyos efectos se sintieron en todo el Imperio (Seiner 2017: 75-82; Silgado 1978). La fecha 1513-1515 difundida en muchas publicaciones del siglo XX se debe a una corrección equivocada, según Seiner (loc. cit.). Creemos muy probable que el evento de 1512 fue responsable de las destrucciones que hemos registrado en casi todos los sectores excavados, seguidos por la improvisada reconstrucción. 
Las crónicas (Estete 1968 [1536]); Pizarro 1968 [1533]) manifiestan que luego de la primera visita, los españoles siguieron su rumbo hacia Jauja. En estos confusos tiempos del ocaso del Tahuantinsuyu, que se iniciaron con la captura de Atahualpa y la derrota de sus huestes, los trabajos de reconstrucción en Pachacamac parecen haber seguido, pero a un ritmo menor. El recinto policromado, reconstruido y pintado de rojo fue remontado en este periodo.

Una secuencia de eventos muy parecida a la que acabamos de describir ha sido registrada durante nuestras excavaciones de las temporadas 2005-6 y 2007 (Makowski 2008; Makowski et al. 2008), llevadas a cabo en el extremo norte en la calle Norte-Sur (unidades SW-A y SW-E, ver Fig. 1). Este segmento de la calle en las afueras de la Segunda Muralla, de 53 metros de largo, se caracteriza por el particular estado de conservación de muros que bordean la calle. Solo una parte del muro oeste de 0.9 metros de ancho en la cabecera, se encuentra de pie y posee una considerable altura máxima de 3.1 metros. Las demás tramas de las dos murallas laterales fueron, al parecer, intencionalmente desmontadas en algunas partes, hasta los cimientos, lo que implicaba la necesidad de cavar una zanja. Las áreas de excavación fueron localizadas en tres lugares estratégicos:

1. Dos unidades distribuidas respectivamente, una en el cruce de la calle Norte-Sur con la calle Este-Oeste, la que bordeaba la fachada de la Segunda Muralla; y la otra en el interior de la portada en la muralla mencionada, por la que se ingresa al área monumental de Pachacamac (Makowski 2008).

2. Una trinchera que atraviesa la calle Norte-Sur con proyección hacia la fachada trasera de la Pirámide con Rampa Nº (PCR 8), en las afueras de la Segunda Muralla.

3. Una unidad en el extremo norte de la calzada de la calle Norte-Sur, la que no continuaba hacia la portada de la Tercera Muralla, contrariamente a las expectativas; sino terminaba invadida por las estructuras y basurales correspondientes al extenso campamento (Makowski 2008).

En todas las unidades mencionadas, la calzada de la calle Norte-Sur guarda la misma relación estratigráfica respecto a la capa de arena estéril (Fig. 15) que corresponde a la superficie enarenada, previa a toda clase de actividades en la zona. El estrato subsiguiente, (Fig. 15, capa « $F »$ ) tiene características de capa de nivelación, con el material cultural mezclado y grumos de argamasa, incluyendo la cerámica diagnóstica del Periodo Horizonte Tardío. Estas evidencias ponen en tela de juicio la hipótesis de Pozzi-Escot y Bernuy (2010) y Bernuy y Pozzi-Escot (2018) quienes afirman que el tramo norte de la calle Norte-Sur fue construido en el Periodo Intermedio Tardío.

Sobre la capa de nivelación antes mencionada, se construyeron los muros que bordean la calle Norte-Sur y también fue vaciado el grueso piso de la misma calzada (Fig. 15 capa «E»). Una capa de arena eólica con un número de superficies sobrepuestas, apisonadas por tránsito en la parte inferior del estrato, (Fig. 15, capa «D1») se acumuló sobre la superficie de la calzada. En medio de este estrato se ubica la boca de la larga trinchera Norte-Sur que visiblemente sirvió para desmontar hasta los cimientos el muro lateral oeste, y, de este modo, recuperar los adobes y las rocas canteadas del revestimiento. Esta y otras partes de las dos murallas tuvieron que ser destruidas por el terremoto, para que tenga sentido el desmontaje parcial de los altos muros y la clausura de la calzada.

Los autores consideran probable que se trate del mismo sismo de gran magnitud, cuyos estragos encontramos en diferentes partes de Pachacamac inca, posiblemente el terremoto de 1512 (Seiner 2017). El material de construcción recuperado de esta manera fue, según toda probabilidad, reutilizado para edificar los cimientos de las estructuras del campamento. Dichas estructuras y niveles de ocupación asociados conforman las capas C y B. En la capa C llama la atención la presencia de estratos sedimentarios, producto de fuertes lluvias. Todas las capas registradas sobre el estéril $(\mathrm{G})$, desde la superficial (A) hasta la F, contienen material cerámico diagnóstico del Periodo Horizonte Tardío (Fig. 15). Esta secuencia se completa con eventos posteriores a la construcción y uso de la calzada de la calle Norte-Sur, gracias a los perfiles estratigráficos registrados en la portada que se abre en la Segunda Muralla (Makowski 2015: 140-141, figs. 5.9, 5.10). Las asociaciones con fragmentos de textos escritos en castellano, que dan el terminus post quem para el evento, sugieren 


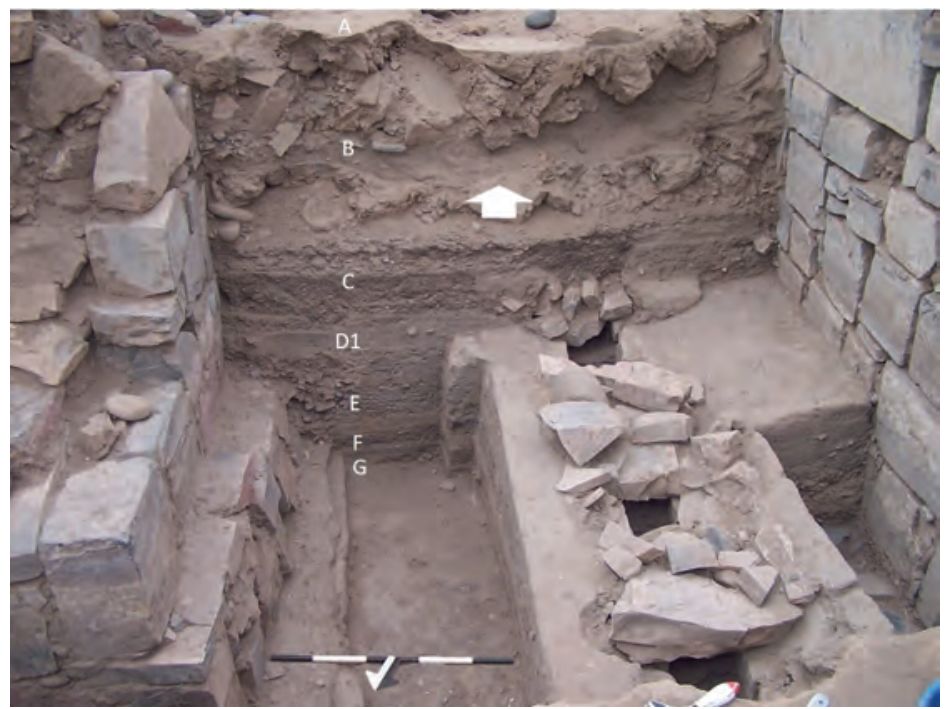

Figura 15. Ingreso a la calle Norte-Sur a través de la Segunda Muralla: perfil sur de la unidad SW-E/2006, nótese el canal. Este estuvo asociado a materiales cerámicos del Horizonte Tardio. En la imagen se incluyen las capas estratigráficas discutidas en el texto. (fotografia: equipo PATL).

que los grandes derrumbes de muros laterales, encima de la gruesa capa de arena eólica que cubre las últimas superficies transitadas de la calle Norte-Sur; correspondería a los estragos causados por uno de los grandes terremotos históricos, el de 1687 o el de 1746 (Seiner 2017). Las evidencias reunidas en nuestras excavaciones de los accesos en la Segunda Muralla demuestran que luego de la clausura de la entrada por la calle Norte-Sur y del desmontaje de sus murallas laterales, hechos relacionados con el terremoto de 1512, se acondicionó una nueva portada en el eje visual que une la portada de la Tercera Muralla con la rampa de la PCR1 (Makowski 2015: 142-144, figs. 5.11) por donde se podía acceder a la zona monumental del Santuario.

Como veremos a continuación, las actividades en Pachacamac no cesaron luego de la primera visita española. Una segunda llegada de los conquistadores al Santuario se habría dado a inicios de 1534, sino antes, como queda confirmado en un documento que cita María Rostworowski (1975: 253) con fecha del 5 de enero de 1534, donde Francisco Pizarro, desde el Tambo de Pachacamac, otorga la encomienda de Chincha a su hermano Hernando. Cuando la Ciudad de los Reyes (Lima) se funda en enero de 1535, Pachacamac se convierte en un paso obligado desde y hacia ella. Las evidencias de ocupación registradas en El Cuadrángulo hacen pensar a los autores que ya, en esta fecha temprana, se había tomado la decisión de transformar el recinto de El Cuadrángulo para que cumpla funciones del componente, tal vez principal, del tambo (Vaca de Castro 2018 [1543]).

La ubicación al final de la calle principal de Pachacamac, la existencia de altas murallas con un solo acceso y la situación del dominio visual sobre todo el asentamiento, incluida la entrada al Templo Pintado, habrán sido tomados en cuenta en dicha decisión. El complejo de la entrada a El Cuadrángulo, con su pasadizo central empedrado y plataformas laterales, quedó parcialmente reconstruido y dotado de una estructura de quincha para el guardián y una atalaya de vigilancia accesible por medio de una rampa. El acceso desde afuera fue dotado, también, de un portón, a juzgar por la huella de dos postes-jambas. Los depósitos y las áreas de producción de chicha, que estaban ubicados en recintos rectangulares, alineados a lo largo de los muros oeste y este, y heredados de tiempos inca, siguieron en uso con ligeras adaptaciones. Hubo, también, renovaciones cuando algunos segmentos de muros se rajaron o incluso colapsaron, dañados por sismos, quizás por los eventos de 1553 y 1555 (Seiner 2017). Los sismos de 1581 y 1586 (ibid.), este último particularmente destructor, acontecieron cuando El Cuadrángulo ya estaba, probablemente, desocupado.

Las mayores actividades constructivas emprendidas por la administración española se concentraron en uno de los montículos artificiales, el de mayor altura, en la parte central del recinto 
cercado por la alta muralla. En la cima de este montículo, que escondía vestigios de actividades Huari e Ychsma Temprano, se realizaban durante la administración inca actividades de preparación de bebidas y, eventualmente, comidas a notable escala, con varios fogones para grandes ollas-paicas. Dichas actividades probablemente acompañaban a la construcción de estructuras decoradas con pinturas murales.

Para poder realizar sus planes de construcción, la administración española movilizó, por supuesto, la mano de obra local que hizo uso de sus métodos y conocimientos. La cima del montículo con vestigios de ocupaciones previas fue nivelada con una gruesa capa de rellenos y se creó un terraplén ascendente desde el Norte para facilitar el acceso de caballos. A pesar de la nivelación, la mayor parte de los muros perimétricos de la estructura rectangular con el corredor central fue dotada de cimientos, a la usanza europea. En la mampostería de los muros se dio uso de adobes y rocas canteadas recuperadas de las construcciones previas. No obstante, tanto el aparejo como las fórmulas de la argamasa y enlucidos corresponden a la tradición prehispánica.

Durante su uso, y en particular poco antes del abandono definitivo, las estructuras del tambo colonial fueron afectadas por varias temporadas de lluvias torrenciales que lavaron los paramentos y las cabeceras de los muros, disolviendo los enlucidos, las argamasas e incluso, los adobes; formándose un limo que luego se volvió a sedimentar sobre las superficies de uso. Así se formó una gruesa capa laminar, particularmente notoria, encima del empedrado de la entrada, donde uno de los sedimentos contenía componentes de un ajuar funerario desparramados en el barro y visiblemente abandonados por los saqueadores coloniales (Makowski 2017).

No se puede, por supuesto, identificar con plena certeza los episodios de fuertes lluvias que dejaron huella en la estratigrafía local con eventos climáticos anormales concretos registrados mediante estudios paleoclimáticos e históricos (Billman y Huckleberry 2008). Sin embargo, hay una acumulación interesante de episodios de paleo-Niño de considerable magnitud en el siglo XVI. Es cierto, que de la lista publicada por Quinn, Neal y Antúnez de Mayolo (1987), Hocquenghem y Ortlieb (1992) confirman solo un evento de gran magnitud en el siglo XVI, el super-Niño de 1578, a partir de una rigurosa crítica de fuentes históricas. Sin embargo, esta lista se incrementa a seis eventos entre 1550 y 1600 que se registran a partir de evidencias paleoclimáticas (GarciaHerrera et al. 2008). Por su lado, Kiracofe y Marr (2008) sustentan, con nuevos argumentos, que el fenómeno de El Niño ocurrió en 1525-26 y 1531-32, a pesar de la crítica al respecto formulada por Hocquenghem y Ortlieb (1992). En la hipótesis de Kiracofe y Marr (2008) el evento habría favorecido el desarrollo de una epidemia de Bartonellosis.

\section{Conclusiones}

El cuidadoso análisis de las secuencias estratigráficas y arquitectónicas invitan a reevaluar las interpretaciones previas, citadas y discutidas a lo largo de este artículo. Estas secuencias provienen de unidades de excavación ubicadas, por los autores, en lugares estratégicos, en las que se esperaría encontrar evidencias concernientes a todos los periodos subsiguientes en la compleja historia ocupacional del asentamiento, como la entrada y el complejo arquitectónico al final de la calle amurallada Norte-Sur, considerada la principal vía del Santuario.

El Pachacamac planificado, cuyos vestigios se presentan en la superficie, corresponde a una obra del Imperio Inca, la que resultó parcialmente afectada, en un grado aún por definir, por el tambo colonial y por el proceso de extirpación de idolatrías. No existe continuidad alguna entre los proyectos emprendidos por la administración incaica y la traza arquitectónica de los periodos anteriores, incluso en el caso emblemático del hipotético templo de Pachacamac, el Templo Pintado. Siglos de destrucción y abandono separan a la plataforma del fin del Periodo Horizonte Medio, de la que se cree proceder el Ídolo bifronte de Pachacamac, y el edificio escalonado con su decoración polícroma figurativa, construido en el Periodo Horizonte Tardío. 
Contrariamente a lo que se podría considerar, el espesor de las capas subsiguientes y la complejidad de la estratigrafía no guarda, en Pachacamac, la proporcionalidad con el carácter de procesos geológicos, sino, con la intensidad y envergadura de las actividades humanas que se han realizado en cada tiempo y lugar. Los periodos que se caracterizan por una mayor complejidad estratigráfica, debido a la gran intensidad de eventos de construcción, reconstrucción y también de actividades ceremoniales, son aquellos que se definen por la presencia de material diagnóstico Lima Medio, por un lado; e Inca e Ychsma Tardío asociados, por el otro. En este último caso, se logran definir varios episodios constructivos y de uso inca, anteriores a la presencia española, y también ocupaciones relacionadas con la transformación de El Cuadrángulo en un tambo colonial durante el siglo XVI, antes de la fundación de la reducción de San Salvador de Pachacamac. Cabe observar, también, el impacto devastador del terremoto de 1512, cuyos efectos no lograron superarse antes de la primera visita española en Pachacamac, así como de lluvias de inusual intensidad.

\section{Agradecimientos}

Extendemos nuestro agradecimiento a la Pontificia Universidad Católica del Perú y a la Asociación UNACEM por el convenio suscrito anualmente, entre ambas entidades, que hacen posible nuestros trabajos ininterrumpidos desde hace 30 ańos. De igual manera, a nuestros colegas del Programa Arqueológico-Escuela de Campo-valle de Pachacamac por su apoyo constante en los trabajos realizados en campo y gabinete.

\section{Notas}

${ }^{1}$ Entre 1570 y 1575, el virrey Toledo realizó una Visita General al Perú entre cuyos objetivos se encontraba el llevar a cabo una campaña de reducción de la población indígena en pueblos de estilo español. Esta tarea tenía como finalidad el reordenamiento de las encomiendas, concentrando a la población indígena en reducciones, alejándolos de sus espacios de adoración (Mumford 2012). El virrey Toledo le encomendó a Rodrigo Cantos de Andrade la visita a la doctrina de Pachacamac y Caringa; y fue el fundador del pueblo San Salvador de Pachacamac en 1572 (Rostworowski 1999, 2002).

2 «Conjunto de procesos geológicos donde predominan la erosión-sedimentación que tiende a regularizar las asperezas o salientes de una superficie topográfica y rellenar las depresiones. En las superficies de peneplanización se observan cerros testigos (monadnocks) compuestos de rocas duras que han resistido a la erosión» (INGEMMET 2011).

\section{Referencias}

Ángeles, R. y D. Pozzi-Escot. (2010). El Horizonte Medio en Pachacamac, en: R. Romero y T. Pavel Svendsen (eds.), Arqueología en el Perú. Nuevos aportes para el estudio de las sociedades andinas prehispánicas, 175-196, Anheb Impresiones, Lima.

Bazán, F. (1990). Arqueología y etnohistoria de los periodos prehispánicos tardíos de la costa central del Perú, tomos I y II. Tesis para optar el grado de Licenciado en Arqueología. Universidad Mayor de San Marcos, Lima.

Bernuy, K. y D. Pozzi-Escot. (2018). Santuario arqueológico Pachacamac: Investigaciones en la ruta de los peregrinos, Ministerio de Cultura, Lima.

Billman, B. R. y G. Huckleberry. (2008). El Niño Events on the North Coast Peru, en: D. H. Sandweiss y J. Quilter (eds.), El Niño. Catastrophism and Culture Change in Ancient America, 101-128, Trustees for Harvard University, Dumbarton Oaks, Washington D.C.

Bonavía, D. (1974). Richcata Quellcani. Pinturas murales prehispánicas, Fondo del Libro del Banco Industrial del Perú, Editorial Ausonia S.A., Lima.

Bonavía, D. (1985). Mural Painting from Ancient Peru, Indiana University Press, Bloomington. 
Cabrera, M. y J. Ochatoma. (2016). El estilo Huamanga: formas e iconografía de la cerámica doméstica, en: M. Giersz y K. Makowski (eds.), Nuevas Perspectivas en la Organización Politica Wari, 287-329, Travaux de l'Institut Français d'Études Andines, Andes 9, Varsovia/Lima.

Curatola, M. (2016). La voz de la huaca. Acerca de la naturaleza oracular y el trasfondo aural de la religión andina antigua, en: M. Curatola y J. Szeminski (comps.), El Inca y la huaca. La religión del poder y el poder de la religión en el mundo andino antiguo, 259-316, The Hebrew University of Jerusalem/Fondo Editorial PUCP, Lima.

Dulanto, J. (2001). Dioses de Pachacamac: el ídolo y el tiempo, en: K. Makowski (ed.), Los Dioses del Antiguo Perú, vol. 2, 159-181, Colección Arte y Tesoros del Antiguo Perú, Banco de Crédito del Perú, Lima.

Eeckhout, P. (1999-2000). The palace of the lords of Ychsma: An archaeological reappraisal of function of pyramids with ramps at Pachacámac, Central Coast of Peru, Revista de Arqueología Americana (17-19), 217-254. https://doi.org/10.36447/Estudios2000.v20.art2

Eeckhout, P. (1999a). Pirámide con rampa NIII, Pachacámac. Nuevos datos, nuevas perspectivas, Bulletin de l'Institut Français d'Études Andines 28(2), 169-214.

Eeckhout, P. (1999b). Pachacámac durant l'Intermédiaire Récent. Étude d'un site monumental prehispánique de la Côte centrale du Pérou, BAR International Series, 747, Paris Monographs in American Archaeology, Hadrian Books Ltd, Oxford.

Eeckhout, P. (2004a). La sombra de Ychsma. Ensayo introductorio sobre la arqueología de la costa central del Perú en los periodos tardíos, en: P. Eeckhout (ed.), Bulletin de l'Institut Français d'Études Andines 33(3), 403-423. https://doi.org/10.4000/bifea.5047

Eeckhout, P. (2004b). Pachacámac y el proyecto Ychsma (1999-2003), Bulletin de l'Institut Français d'Études Andines 33(3), 425-448. https://doi.org/10.4000/bifea.5049

Eeckhout, P. (2004c). Reyes del sol y señores de la luna. Inkas e Ychsmas en Pachacámac, Chungará 36(2), 495-503. https://doi.org/10.4067/S0717-73562004000200019

Eeckhout, P. (2010a). Las pirámides con rampa de Pachacámac durante el Horizonte Tardío, en: R. Romero y T. P. Svendsen (eds.), Arqueología en el Perú: nuevos aportes para el estudio de las sociedades andinas prehispánicas, 415-434, Anheb Impresiones, Lima.

Eeckhout, P. (2010b). Nuevas evidencias sobre costumbres funerarias en Pachacámac, en: P. Kaulicke, M. Fischer, P. Masson y G. Wolff (eds.), Max Uble (1856-1944): Evaluaciones de sus Investigaciones y Obras, 151-163, Fondo Editorial PUCP, Lima.

Eeckhout, P. (2018). The Middle Horizon and Southern Andean Iconographic Series on the Central Coast of Peru, en: W. Isbell, M. Uribe, A. Tiballi y E. Zegarra (eds.), Images in action, the southern Andean iconographic series, 533-569, UCLA Cotsen Institute of Archaeology Press, Los Angeles.

Esquivel y Navia, D. (1901 [1740]). Apuntes históricos del Perú y noticias cronológicas del Cuzco (Anales). Periodo 1543-1610, Lima.

Estete, M. de (1968 [1534]). La relación del viaje que hizo el señor Capitán Hernando Pizarro por Mandado del señor Gobernador, su hermano, desde el pueblo de Caxamalca a Pargama (Pachacamac) y de allí a Jauja, en: F. de Xerez, Verdadera Relación de la Conquista del Perú y provincia del Cuzco llamada la Nueva Castilla, 242-257, tomo I, Primera Serie, Biblioteca Peruana, Lima.

Estete, M. de (1968 [1536]). Noticia del Perú, Biblioteca Peruana, Primera Serie, 345-402, tomo I, Editores Técnicos Asociados S.A, Lima.

Estete, M. de (1985 [1534]). La relación del viaje que hizo el señor capitán Hernando Pizarro por mandado del señor Gobernador, su hermano, desde el pueblo de Caxamalca a Parcama y de allí a Jauja, en: C. Bravo (ed.), Francisco de Xerez, Verdadera relación de la conquista del Perú, 130-148, Historia 16, Madrid.

Franco, R. (2004). Poder religioso, crisis y prosperidad en Pachacamac: Del Horizonte Medio al Intermedio Tardío, en: P. Eeckhout (ed.), Arqueología de la Costa Central del Perú en los periodos tardíos, Bulletin de Institut Francais d'etudes Andines 33(3), 465-506. https://doi.org/10.4000/bifea.5074

Franco, R. y P. Paredes (1985). Excavaciones en la Huaca Pintada o el Templo de Pachacamac, Boletín de Lima 7(41), 78-84.

Franco, R. y P. Paredes (2016). Templo Viejo de Pachacamac. Dioses, arquitectura, sacrificios y ofrendas, Institute of Andean Research-Fundación Wiesse, Lima.

García-Herrera, R., D. Barriopedro, E. Hernández, H. F. Díaz, R. R. García, M. R. Prieto y R. Moyano (2008). A chronology of El Niño events from primary documentary sources in Northern Peru, Journal of Climate 21(9), 1948-1962. https://doi.org/10.4000/bifea.5074

Garcilaso de la Vega, I. (1985[1609]). Comentarios reales de los incas, Banco de Crédito del Perú, Lima.

Giesecke, A. (1938). Archivo Albert Giesecke - Documentos (Folder: AG-D-194; AG-D-195; AG-D-0221; AG-D1261), Instituto Riva Agüero, Pontificia Universidad Católica del Perú, Lima. 
Hocquenghem, A. M. y L. Ortlieb (1992). Eventos El Niño y lluvias anormales en la Costa del Perú: siglos XVI-XIX, Bulletin de l'Institut Français d'Études Andines 21(1), 197-278.

Instituto Geológico Minero y Metalúrgico (INGEMMET) (1995). Geología del Perú, INGEMMET, Lima.

Instituto Geológico Minero y Metalúrgico (INGEMMET) (2011). Diccionario geológico, INGEMMET, Lima.

Jacay, J. y J. Oshiro (2015). Estudio geológico de la laguna urpiwachaq, en: D. Pozzi-Escot y J. Oshiro (eds.), Urpiwachaq: gestión y puesta en valor de la laguna, 21-38, Ministerio de Cultura del Perú y Universidad Pacífico, Lima.

Jiménez Borja, A. (1985). Pachacamac, Boletín de Lima 38, 40-54.

Kiracofe, J. B. y J. S. Marr (2008). Marching to Disaster: The Catastrophic Convergence of Inca Imperial Policy, Sand Flies, and El Niño in the 1524 Andean Epidemic, en: Daniel H. Sanweiss y J. Quilter, El Niño. Catastrophism and Culture Change in Ancient America, 33-55, Trustees for Harvard University, Dumbarton Oaks, Washington D.C.

Lumbreras, L. (2017). Los Wari en Pachacamac, en: D. Pozzi-Escot, S. G. Millones y A. J. Canziani (eds.), Pachacamac: El oráculo en el horizonte marino del sol poniente, 97-113, Banco de Crédito del Perú, Lima.

Macharé, J. (1981). Geología del Cuaternario de la costa del Perú central, tesis, Universidad Nacional de Ingeniería, Lima.

Macharé, J. y L. Ortlieb (1993). Registros del fenómeno El Niño en el Perú, Bulletin de l'Institut Français d'Études Andines 22, 35-52.

Macharé, J., M. Sebrier, D. Huaman y J. Mercier (1986). Tectónica cenozoica de la margen continental peruana, Boletín de la Sociedad Geológica del Perú 76, 45-77.

Makowski, K. (2008). Proyecto Arqueológico - Taller de Campo PUCP - Lomas de Lurín - PATL, informe final Temporada 2007 (Campo y Gabinete), manuscrito no publicado enviado al INC, Lima.

Makowski, K. (2009). Proyecto Arqueológico - Taller de Campo - Lomas de Lurín - PATL, informe final temporada 2009 (Campo y Gabinete), manuscrito no publicado enviado al INC, Lima.

Makowski, K. (2013). Programa Arqueológico - Taller de Campo - Valle de Pachacamac - PATL, informe final temporada 2011-2012 (Campo y Gabinete), manuscrito no publicado enviado Ministerio de Cultura, Lima.

Makowski, K. (2015). Pachacamac-old wak'a or Inka syncretic deity? en: T. L. Bray (ed.), The archaeology of Wak'as: Explorations of the sacred in pre-Columbian Andes, 127-166, University Press of Colorado, Boulder. https://doi. org/10.5876/9781607323181.c005

Makowski, K. (2016a). Pachacamac y la política imperial inca, en: M. Curatola y J. Szeminski (eds.), El inca y la huaca. La religión del poder y el poder de la religión en el mundo antiguo, 153-208, The Hebrew University of Jerusalem/Fondo Editorial PUCP, Lima.

Makowski, K. (2016b). Urbanismo andino: centro ceremonial y ciudad en el Perú prehispánico, Apus Graph, Lima.

Makowski, K. (2017). Programa Arqueológico - Taller de Campo - Valle de Pachacamac - PATL, informe final temporada 2016 (Campo y Gabinete), manuscrito no publicado enviado al Ministerio de Cultura, Lima.

Makowski, K. (2019). Programa Arqueológico - Taller de Campo - Valle de Pachacamac - PATL, informe final temporada 2017 (Campo y Gabinete), manuscrito no publicado enviado Ministerio de Cultura, Lima.

Makowski, K. y C. Vargas (2019). Los tesoros culturales de la PUCP. Colección Programa Arqueológico "valle de Pachacamac», tomo 8, Lluvia editores, Lima.

Makowski, K., I. Ghezzi, D. Guerrero, H. Neff, M. Jiménez, G. Oré y R. Álvarez-Calderon (2008). Pachacamac, Ychsma y los Caringas: estilos e identidades en el valle de Lurín Inca, en: O. Pinedo y H. Tantaleán (comps.), Arqueología de la costa centro sur peruana, 267-316, Aqvi Editores, Lima.

Menzel, D. (1964). Style and time in the Middle Horizon, Nawpa Pacha 2, 1-106. https://doi.org/10.1179/ naw.1964.2.1.001

Muelle, J. C. y R. Wells (1939). Las pinturas del Templo de Pachacamac, Revista del Museo Nacional 8, 275-282.

Mumford, J. (2012). Vertical empire. The general resettlement of indians in the colonial Andes. Duke University Press, Durham. https://doi.org/10.1515/9780822395591

Ochatoma, J. (2007). Alfareros del Imperio Huari. Vida Cotidiana y áreas de actividad en Conchopata, Universidad Nacional de San Cristóbal de Huamanga, Ayacucho.

Paredes, P. (1985). La Huaca Pintada o el Templo de Pachacamac, Boletín de Lima 41, 70-77. https://doi. org/10.36576/summa.5438

Patterson, T. (1966). Pattern and process in the Early Intermediate Period pottery of the Central Coast of Peru, University of California Publications in Anthropology, vol. 3, University of California Press, Berkeley/Los Angeles.

Peralta, A. (2021). Secuencia arquitectónica en la Sala Central, Museo de Sitio de Pachacamac, Ministerio de Cultura del Perú, Lima. http://pachacamac.cultura.pe/sites/default/files/secuenciaarquitectonicasalacentral.pdf 
Pizarro, H. (1968 [1533]). Carta de Hernando Pizarro a los magníficos señores, los señores oidores de la Audiencia Real de Su Majestad, que residen en la ciudad de Santo Domingo, Biblioteca Peruana, Primera Serie, tomo I, 117-130, Lima.

Pozzi-Escot, D. y K. Bernuy (2010). Pachacamac: Calle Norte-Sur: Investigaciones arqueológicas, Museo de Sitio de Pachacamac, Ministerio de Cultura del Perú, Lima.

Pozzi-Escot, D., S. G. Millones y A. J. Canziani. (2017). Pachacamac: El oráculo en el horizonte marino del sol poniente, Banco de Crédito del Perú, Lima.

Praet, E., S. Byl, P. Eeckhout y M. Luján. (2017). Evidencias arqueológicas de la conquista hispana y el periodo de transición halladas por el Proyecto Ychsma en el edificio B4 de Pachacamac, valle de Lurín (2016). Revista Haucaypata. Investigaciones Arqueológicas del Tahuantinsuyo 12, 6-22.

Quinn, W. H., W. Neal y S. Antúnez de Mayolo (1987). El Niño occurrences over the past four and a half centuries, Journal of Geophysical Research, 92 (C13), 14449-14461. https://doi.org/10.1029/JC092iC13p14449

Ramos, J. (2011). Santuario de Pachacamac: Cien años de arqueología en la Costa Central, Editorial Cultura Andina, Lima.

Ramos, J. y P. Paredes. (2010) Excavaciones en la segunda muralla-sector Puente Lurín. Correlación estratigráfica de los estilos cerámicos durante el Horizonte Tardío en el santuario de Pachacamac, Bulletin de Institut Francais d'etudes Andines 39(1), 105-166. https://doi.org/10.4000/bifea.2173

Ravines, R. (1996). Pachacamac: Santuario universal, Editorial Los Pinos, Lima.

Rostworowski, M. (1975). Pescadores, artesanos y mercaderes costeños en el Perú prehispánico, Revista del Museo Nacional XLI [Recogido de Etnia y sociedad, 211-271, y Costa peruana prehispánica, 263-292], Lima.

Rostworowski, M. (1999). El señorio de Pachacamac: el informe de Rodrigo Cantos de Andrade. Instituto de Estudios Peruanos - Banco Central de Reserva del Perú, Lima.

Rostworowski, M. (2002). Pachacamac y el Señor de los Milagros: una trayectoria milenaria; El Señorio de Pachacamac: el informe de Rodrigo Cantos de Andrade; Señorios indigenas de Lima y Canta. Obras Completas II, Historia Andina, 25. Instituto de Estudios Peruanos, Lima.

Sandweiss, D. y J. Quilter (2012). Collation, correlation, and causation in the prehistory of coastal Peru, en: J. Cooper y P. Sheets (eds.), Survival sudden environmental change, 117-141, University Press of Colorado, Colorado. https://doi.org/10.2307/j.ctt1wn0rbs.10

Seiner, L. (2017). Historia de los sismos en el Perú: Catálogo: siglos XV-XVI, Fondo Editorial Universidad de Lima, Lima.

Sepúlveda, M., D. Pozzi-Escot, R. Ángeles, N. Bermeo, M. Lebon, C. Moulhérat, P. Sarrazin y P. Walter (2020). Unraveling the polychromy and antiquity of the Pachacamac Idol, Pacific coast, Peru, Journal Community Plos One 15(1): e0226244. https://doi.org/10.1371/journal.pone.0226244

Shimada, I. (1991). Pachacamac archaeology: Retrospect and prospect. An introduction, en: Uhle, M. (1991 [1903]) Pachacamac, by Max Uble (1903). Report of the William Pepper, M.D., LL.D., Peruvian Expedition of 1896 (Introducción de I. Shimada), XV-LXVIII, University Museum Monograph 62, The University Museum of Archaeology and Anthropology, University of Pennsylvania, Philadelphia.

Shimada, I. (2007). Las prospecciones y excavaciones en Urpi Kocha y Urpi Wachak: Estudio preliminar, Cuadernos de Investigación del Archivo Tello 5, 13-18, Museo de Arqueología y Antropología, Universidad Nacional Mayor de San Marcos, Lima.

Shimada, I., R. Segura, D. Goldstein, K. Knudson, M. Shimada, K. Shinoda, M. Takigami y U. Wagner. (2010). Un siglo después de Uhle: Reflexiones sobre la arqueología de Pachacamac y Perú, en: P. Kaulicke, M. Fischer, P. Masson \& G. Wolff (eds.), Max Uhle (1856-1944). Evaluaciones de sus investigaciones y obras, 109-150, Fondo Editorial PUCP, Lima.

Silgado, E. (1978). Historia de los sismos más notables ocurridos en el Perú (1513-1574), Boletín Serie C: Geodinámica e Ingeniería Geológica, 3.

Strong, W. y J. Corbett (1943). A ceramic sequence at Pachacamac, en: W.D. Strong, G.R. Willey y J.M. Corbett (eds.), Archaeological studies in Peru, 1941-1942, 27-122, Columbia Studies in Archaeology and Ethnology, vol. 1, No2, Columbia University Press, New York. https://doi.org/10.7312/stro90392-003

Tello, J. C. (1940). Pachacamac, Chaski, 1(2): 1-4.

Tello, J. C. (1960). Guía de las ruinas de Pachacamac, Tipografía Peruana, Lima.

Tello, J. C. (2007). Arqueología de Pachacamac: Excavaciones en Urpi Kocha y Urpi Wachak, Cuadernos de Investigación del Archivo Tello $N^{\circ} 5$, Museo de Arqueología y Antropología de la Universidad Nacional Mayor de San Marcos, Lima. 
Uhle, M. (2003 [1903]). Pachacamac. Informe de la expedición peruana William Pepper de 1896. Primera edición: Universidad de Pensilvania, Filadelfia, 1903. [Primera edición en castellano, traductor: M. Beltroy Vera], Serie Clásicos Sanmarquinos, COFIDE/Fondo Editorial de la Universidad Nacional Mayor de San Marcos, Lima. Vaca de Castro, C. (2018 [1543]). Ordenanzas de tambos (Cusco 1543), Qhapac Nan, Lima.

Winsborough, B., I. Shimada, L. Newsom, J. Jones y R. Segura (2012). Paleoenvironmental catastrophies on the Peruvian coast revealed in lagoon sediment cores from Pachacamac, Journal of Archaeological Science 39-3, 602-614. https://doi.org/10.1016/j.jas.2011.10.018

Recibido: diciembre 2020

Aceptado: marzo 2021 